\title{
Status of the NASA's Evolutionary Xenon Thruster (NEXT) Long-Duration Test After 30,352 Hours of Operation
}

Daniel A. Herman

Glenn Research Center, Cleveland, Ohio 


\section{NASA STI Program . . . in Profile}

Since its founding, NASA has been dedicated to the advancement of aeronautics and space science. The NASA Scientific and Technical Information (STI) program plays a key part in helping NASA maintain this important role.

The NASA STI Program operates under the auspices of the Agency Chief Information Officer. It collects, organizes, provides for archiving, and disseminates NASA's STI. The NASA STI program provides access to the NASA Aeronautics and Space Database and its public interface, the NASA Technical Reports Server, thus providing one of the largest collections of aeronautical and space science STI in the world. Results are published in both non-NASA channels and by NASA in the NASA STI Report Series, which includes the following report types:

- TECHNICAL PUBLICATION. Reports of completed research or a major significant phase of research that present the results of NASA programs and include extensive data or theoretical analysis. Includes compilations of significant scientific and technical data and information deemed to be of continuing reference value. NASA counterpart of peer-reviewed formal professional papers but has less stringent limitations on manuscript length and extent of graphic presentations.

- TECHNICAL MEMORANDUM. Scientific and technical findings that are preliminary or of specialized interest, e.g., quick release reports, working papers, and bibliographies that contain minimal annotation. Does not contain extensive analysis.

- CONTRACTOR REPORT. Scientific and technical findings by NASA-sponsored contractors and grantees.
- CONFERENCE PUBLICATION. Collected papers from scientific and technical conferences, symposia, seminars, or other meetings sponsored or cosponsored by NASA.

- SPECIAL PUBLICATION. Scientific, technical, or historical information from NASA programs, projects, and missions, often concerned with subjects having substantial public interest.

- TECHNICAL TRANSLATION. Englishlanguage translations of foreign scientific and technical material pertinent to NASA's mission.

Specialized services also include creating custom thesauri, building customized databases, organizing and publishing research results.

For more information about the NASA STI program, see the following:

- Access the NASA STI program home page at http://www.sti.nasa.gov

- E-mail your question via the Internet to help@ sti.nasa.gov

- Fax your question to the NASA STI Help Desk at $443-757-5803$

- Telephone the NASA STI Help Desk at 443-757-5802

- Write to: NASA Center for AeroSpace Information (CASI) 7115 Standard Drive Hanover, MD 21076-1320 


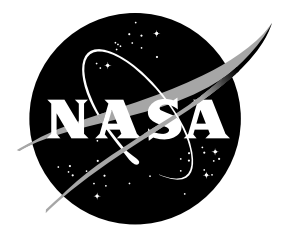

\section{Status of the NASA's Evolutionary Xenon Thruster (NEXT) Long-Duration Test After 30,352 Hours of Operation}

Daniel A. Herman

Glenn Research Center, Cleveland, Ohio

Prepared for the

46th Joint Propulsion Conference and Exhibit

cosponsored by the AIAA, ASME, SAE, and ASEE

Nashville, Tennessee, July 25-28, 2010

National Aeronautics and

Space Administration

Glenn Research Center

Cleveland, Ohio 44135 


\section{Acknowledgments}

The author would like thank the entire NEXT ion team at NASA GRC and JPL for their support of the NEXT LDT, input to the test execution, and assistance interpreting the testing data and behavior. In particular, George Soulas has provided invaluable guidance, logistical support for the test execution, and technical support. Special thanks to Jonathan Van Noord for providing details and data relating to the NEXT thruster service life assessment for inclusion in this paper and comparison to measured LDT data. The author would like to thank the facilities staff for their extraordinary effort to maintain vacuum conditions for over 5 years continuously through various power and water outages as well as other obstacles.

This report contains preliminary findings, subject to revision as analysis proceeds.

Level of Review: This material has been technically reviewed by technical management.

Available from

NASA Center for Aerospace Information 7115 Standard Drive

Hanover, MD 21076-1320
National Technical Information Service 5301 Shawnee Road Alexandria, VA 22312 


\title{
Status of the NASA's Evolutionary Xenon Thruster (NEXT) Long-Duration Test After 30,352 Hours of Operation
}

\author{
Daniel A. Herman \\ National Aeronautics and Space Administration \\ Glenn Research Center \\ Cleveland, Ohio 44135
}

\begin{abstract}
The NASA's Evolutionary Xenon Thruster (NEXT) program is developing the next-generation solarelectric ion propulsion system with significant enhancements beyond the state-of-the-art NASA Solar Electric Propulsion Technology Application Readiness (NSTAR) ion propulsion system to provide future NASA science missions with enhanced mission capabilities. As part of a comprehensive thruster service life assessment utilizing both testing and analyses, a Long-Duration Test (LDT) was initiated in June 2005 to validate the thruster service life modeling and to qualify the thruster propellant throughput capability. The NEXT ion propulsion system can be throttled from 0.5 to $6.9 \mathrm{~kW}$ to accommodate varying available power levels during missions. The NEXT LDT has been operated in an outbound mission-like profile consisting of throttling down in thruster input power. Operating conditions were selected based upon their interest relative to component wear mechanisms and potential performance variations. The planned throttling profile has been completed and the thruster has subsequently been throttled to fullpower, the condition predicted to reach thruster failure in the least amount of time. Thruster performance has been steady with negligible degradation, less than 0.5 percent increase in input power compared to beginning-of-life. Component erosion rates and progression of the predicted life-limiting erosion mechanism for the thruster compare favorably to pretest predictions based upon semi-empirical ion thruster models used in the thruster service life assessment. Service life model validation has been accomplished by the NEXT LDT.

The thruster has set the record for the longest operating duration of any ion or Hall thruster; the record was previously held by the NSTAR extended life test. At the time of this publication, the NEXT LDT has surpassed 30,352 $\mathrm{h}$ of operation, processed more than $495 \mathrm{~kg}$ of xenon propellant, and demonstrated greater than 18.2 MN·s total impulse. The NEXT thruster has set records for total hours of operation, total propellant throughput processed, and total impulse demonstrated for any ion or Hall thruster. The project qualification-level throughput of $450 \mathrm{~kg}, 1.5$ times the anticipated throughput requirement of $300 \mathrm{~kg}$ per thruster from mission analyses, was demonstrated in CY2009. The design improvements for the NEXT thruster based upon the NSTAR knowledge gained have successfully mitigated several lifetime limiting mechanisms encountered in the NSTAR design, including the NSTAR first failure mode encountered, thereby drastically improving thruster capabilities. Assuming full-power operation until test article failure, the models and extrapolated erosion data predict thruster failure due to degradation of the accelerator grid structural integrity after $>45,000 \mathrm{~h}$ of operation while processing over $800 \mathrm{~kg}$ of xenon propellant.
\end{abstract}

\section{Nomenclature}

$\begin{array}{ll}\text { AC } & \text { alternating current } \\ \text { BOL } & \text { beginning-of-life } \\ \text { CRA } & \text { center radius aperture } \\ \text { DC } & \text { direct current } \\ \text { DCA } & \text { discharge cathode assembly } \\ \text { DS1 } & \text { Deep Space 1 mission } \\ \text { DSDRM } & \text { deep space design reference mission }\end{array}$




$\begin{array}{ll}\text { ELT } & \text { extended life test } \\ \text { EM } & \text { engineering model } \\ \text { EM3 } & \text { engineering model } 3 \text { thruster } \\ \text { EPIC } & \text { Electric Propulsion Interactions Code } \\ \text { GRC } & \text { NASA Glenn Research Center } \\ \text { HiPEP } & \text { High-Power Electric Propulsion } \\ \text { IPS } & \text { ion propulsion system } \\ \text { I }_{\text {sp }} & \text { specific impulse, s } \\ \text {J}_{\text {B }} & \text { beam current, A } \\ \text { J }_{\text {NK }} & \text { neutralizer keeper current, A } \\ \text { LDT } & \text { long-duration test } \\ \text { NCA } & \text { neutralizer cathode assembly } \\ \text { NEAR } & \text { Near Earth Asteroid Rendezvous mission } \\ \text { NEXT } & \text { NASA's Evolutionary Xenon Thruster } \\ \text { NSTAR } & \text { NASA Solar Electric Propulsion Technology Application Readiness } \\ \text { ORA } & \text { outer-radius aperture } \\ \text { PM } & \text { prototype model } \\ \text { SSR } & \text { surface sample return } \\ \text { T } & \text { thrust, mN } \\ \text { TL } & \text { throttle level } \\ \text { TT10 } & \text { throttle table10 } \\ V_{B} & \text { beam power supply voltage, V } \\ \text { VF } & \text { vacuum facility } \\ \text { WT } & \text { wear test } \\ \varphi & \text { aperture or orifice diameter } \\ & \end{array}$

\section{Introduction}

NASA identified the need for a higher-power, higher-specific impulse, higher-thrust, and higherthroughput capable ion propulsion system (IPS) beyond the state-of-the-art NASA Solar Electric Propulsion Technology Applications Readiness (NSTAR) IPS employed on the Deep Space 1 and Dawn missions (Refs. 1 to 4). In response to this need, NASA offered the competition for development of such a propulsion system. The NASA Evolutionary Xenon Thruster (NEXT) ion propulsion system, led by the NASA Glenn Research Center (GRC), was competitively selected in 2002. The NEXT IPS has been in advanced technology development under the NASA In-Space Propulsion Technology project. The highest fidelity NEXT hardware has been built by the government/industry NEXT team including: an engineering model thruster, an engineering model power processing unit, engineering model propellant management assemblies, a prototype gimbal, and control unit simulators (Ref. 5). Each of the units have been extensively tested separately, have completed environmental testing (with the exception of the power processing unit which is ongoing), and have been tested together in system integration testing (Refs. 6 and 9). The status of the NEXT project, results from IPS component testing, and results of integration testing can be found in References 5 to 15 .

The NEXT thruster service life capability is being assessed via a comprehensive service life validation scheme utilizing a combination of testing and analyses. The approach is consistent with the lifetime qualification standard for electric thrusters (Ref. 16). The NEXT ion thruster is an evolution of the NSTAR thruster design. The understanding of plasma physics and erosion processes gained from the NSTAR development program also applies to the NEXT thruster. The NEXT thruster, as a second generation deep-space ion thruster, made use of over 58,000 h of ground and flight test experience (not including that from the ongoing Dawn mission) in both the design of the NEXT thruster and evaluation of thruster wear-out failure modes. Effective design iteration should, and will be shown to, address the previous design issues and failure modes. A NEXT service life assessment was conducted at GRC 
employing several models to evaluate all known failure modes with high confidence based upon the substantial amount of ion thruster testing dating back to the early 1960s (Refs. 17 and 18). The NEXT service life assessment also incorporated the results of the NEXT 2,000 $\mathrm{h}$ wear test conducted on a NEXT engineering model ion thruster at $6.9 \mathrm{~kW}$ input power (Refs. 17 and 19). The transparency between engineering and prototype-model thruster wear characteristics has been demonstrated by a short-duration prototype-model wear test (Refs. 20 and 21). The NEXT service life assessment references explain the thruster performance and erosion modeling analyses (Refs. 17 and 18).

The NEXT Long-Duration Test (LDT) was initiated to validate the NEXT thruster service life model and qualify the NEXT thruster lifetime. The goals of the NEXT LDT were to: demonstrate the project qualification propellant throughput requirement of $450 \mathrm{~kg}$, validate thruster service life modeling predictions, quantify thruster performance and erosion as a function of engine wear and throttle level, and identify unknown life-limiting mechanisms. After demonstration of the qualification propellant throughput, $450 \mathrm{~kg}$ of xenon, in CY09 the first listed goal has been redefined to test to failure of the thruster.

\section{NEXT Long-Duration Test Background}

The NEXT LDT is being conducted in VF16 at GRC with an engineering model ion thruster, designated EM3, shown in Figure 1. The EM3 thruster has been modified to a flight-representative configuration by incorporating prototype-model (PM) ion optics, delivered by industry partner Aerojet Corporation, and a graphite discharge cathode keeper electrode (Ref. 22). The NEXT thruster is nominally a 0.5 to $6.9 \mathrm{~kW}$ input power xenon ion thruster utilizing two-grid, dished-out ion optics. The technical approach for the NEXT design is a continuation of the derating philosophy used for the NSTAR ion thruster. A beam extraction area 1.6 times that of NSTAR allows higher thruster input power while maintaining low voltages and ion current densities, thus maintaining thruster longevity. Descriptions of the NEXT EM3 thruster design and VF16 can be found in References 1, 20, and 23 to 27.

Critical ion engine component erosion rates are monitored by six in-situ, charge-coupled device cameras. The cameras record the downstream neutralizer keeper and cathode orifice plates, the discharge keeper and cathode orifice plates, accelerator grid apertures at various radial locations from centerline, and the cold grid-gap of the thruster ion optics. The cameras are mounted to a single-axis positioning system that moves the cameras radially in front of the thruster, typically while the thruster is not

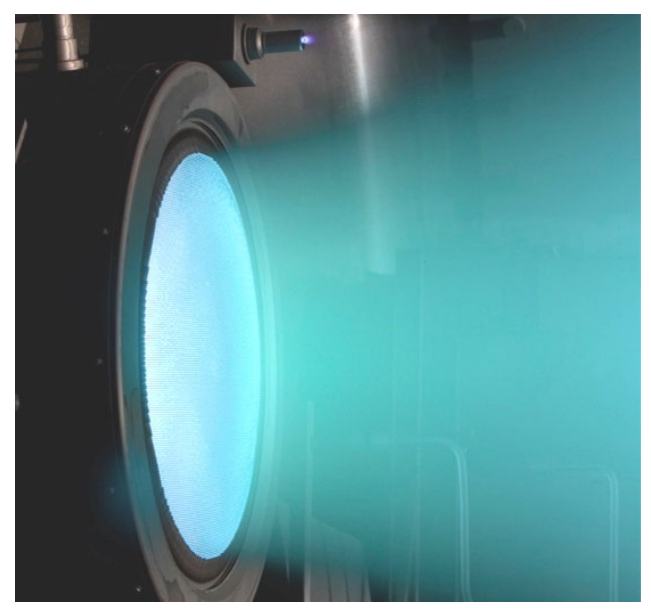

Figure 1.-NEXT EM3 operating at full power during the LDT. 
operating. Additional testing diagnostics include: a data acquisition system that monitors thruster telemetry at $15 \mathrm{~Hz}$ permitting autonomous operation, staggered planar probes to monitor beam profiles and divergence, a quartz-crystal microbalance to monitor backsputtered efflux, and a far-field ExB probe to measure the charge-state signature of the plume. Descriptions of the testing and facility diagnostics can be found in References 27 and 28.

\section{Qualification Throughput and Throttling Profile}

The NEXT IPS is designed for solar electric propulsion applications that experience variation in power available as solar flux changes at various distances from the sun throughout the mission. To accommodate this variation in available power, the IPS is therefore designed to be throttled from 0.5 to $6.9 \mathrm{~kW}$. In addition, the NEXT IPS is designed for broad mission capture, thereby improving the return of investment, accomplished by a wide throttle range of varying specific impulse and thrust values. The project-level qualification throughput (i.e., thruster service life measured in $\mathrm{kg}$ of xenon propellant processed) was determined based upon the individual thruster requirements for proposed missions that would utilize the NEXT IPS. Nine mission analyses performed baselining the NEXT IPS for primary propulsion indicated a maximum individual thruster throughput requirement of $300 \mathrm{~kg}$ (Ref. 17). A margin of 50 percent was placed on this throughput requirement to form the project qualification throughput of $450 \mathrm{~kg}$ for the NEXT thruster. This 50 percent margin has heritage with an early Comsat requirement that thrusters be qualified for life by test with durations equal to 1.5 times the mission life (Ref. 16).

The EM3 thruster is being operated in the NEXT LDT at discrete operating segments for sufficient durations to characterize erosion rates and performance as a function of time for each condition used in validating the thruster service life models. The NEXT throttle table, with 40 discrete operating conditions for the development program, is shown in Figure 2. Detailed thruster characterizations are performed periodically to assess performance over 11 out of 40 of the operating conditions distributed across the NEXT throttle table, shown in Figure 2. Thruster assessment includes overall thruster and component performance including the performance of the discharge chamber, ion optics, and neutralizer cathode. The NEXT throttle table10 (TT10) inputs, used for the LDT, are defined in Reference 29.

\begin{tabular}{|c|c|c|c|c|c|c|c|c|c|c|c|c|c|}
\hline & \multicolumn{13}{|c|}{ Beam power supply voltage } \\
\hline \multirow{9}{*}{ 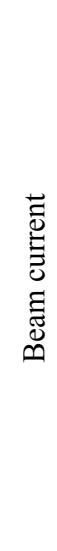 } & & 1800 & 1567 & 1396 & 1179 & 1021 & 936 & 850 & 679 & 650 & 400 & 300 & 275 \\
\hline & 3.52 & 1 & & & 2 & & & & & & & & \\
\hline & 3.10 & & & & & & & & & & & & \\
\hline & 2.70 & & & & & & & & & & & & \\
\hline & 2.35 & & & & & & & & & & & & \\
\hline & 2.00 & & & & & & & & & & & & \\
\hline & 1.60 & & & & & & & & & & & & \\
\hline & 1.20 & 5 & & & & & & & 3 & & & & \\
\hline & 1.00 & & & & & & & & & & & & 4 \\
\hline
\end{tabular}

Figure 2.-Forty operating conditions in the NEXT throttle table. NEXT LDT run segments are numbered chronologically: 1) TL40, 2) TL37, 3) TL05, 4) TL01, and 5) TL12. Periodic performance conditions are shown in red. 
The long-term operating segment selection process focused on operating conditions of interest with regard to wear characteristics and life-limiting phenomena. The NEXT LDT has been operated for extended duration at five operating conditions that span the throttle range in an outbound mission-like profile that decreases the input power with testing duration, shown in Figure 2 and listed in Table 1. After completion of the planned throttling profile, the thruster is operated at full input-power (TL40) until failure. These five conditions were selected to capture the most severe erosion mechanisms, envelope the throttle table, and validate thruster service life model predictions. This throttling strategy demonstrates operation over the extremes of the NEXT throttling table including: highest power (TL40), highest total accelerating voltage (TL40 and TL12), highest thermal load (TL37), worst under-focusing at centerradius aperture location (TL37), highest ratio of discharge cathode emission to discharge cathode flow rate (TL37), worst over-focusing at outer-radius locations (TL12), lowest power (TL01), lowest total accelerating voltage (TL01), lowest thermal load (TL01), and most divergent beam (TL01). TL05 is a low-power condition selected for broad throttle table coverage for model validation and to assess lowpower processes such as neutralizer clogging.

The NEXT thruster service life modeling tools are being applied to assess thruster wear and performance for the specific throttling profiles of potential mission opportunities (Refs. 11 and 18). The life assessment predicts the earliest thruster failure, minimum thruster service life, occurring for fullpower operation after greater than $750 \mathrm{~kg}$ of xenon throughput. All wear testing data support a NEXT thruster service life capability greater than $750 \mathrm{~kg}$, well beyond the mission-derived propellant throughput requirement of $300 \mathrm{~kg}$ (Refs. 17 to 19, 26 to 28, and 30).

TABLE 1.-NEXT LDT MISSION-LIKE THROTTLING STRATEGY

[After throttling profile completion, the thruster is operated at full input power (TL40) until failure.]

\begin{tabular}{|c|c|c|c|c|c|c|}
\hline $\begin{array}{c}\text { Throttle } \\
\text { level }\end{array}$ & $\begin{array}{c}\text { Input } \\
\text { power, } \\
\mathrm{kW}\end{array}$ & $\begin{array}{c}\text { Operating } \\
\text { condition } \\
\left(\mathrm{J}_{\mathrm{B}}, \mathrm{V}_{\mathrm{B}}\right)\end{array}$ & $\begin{array}{c}\text { Segment } \\
\text { duration, } \\
\mathrm{kh}\end{array}$ & $\begin{array}{c}\text { Segment } \\
\text { throughput, } \\
\mathrm{kg}\end{array}$ & $\begin{array}{c}\text { Segment total } \\
\text { impulse, } \\
\mathrm{N} \cdot \mathrm{sec}\end{array}$ & $\begin{array}{c}\text { End of } \\
\text { segment date }\end{array}$ \\
\hline TL40 & 6.9 & $3.52 \mathrm{~A}, 1800 \mathrm{~V}$ & 13.0 & 264.7 & $1.09 \times 10^{7}$ & November 17,2007 \\
\hline TL37 & 4.7 & $3.52 \mathrm{~A}, 1179 \mathrm{~V}$ & 6.5 & 132.6 & $4.45 \times 10^{6}$ & December 23,2008 \\
\hline TL05 & 1.1 & $1.20 \mathrm{~A}, 679 \mathrm{~V}$ & 3.4 & 26.7 & $6.30 \times 10^{5}$ & June 24,2009 \\
\hline TL01 & 0.5 & $1.00 \mathrm{~A}, 275 \mathrm{~V}$ & 3.2 & 23.4 & $3.39 \times 10^{5}$ & December 15,2009 \\
\hline TL12 & 2.4 & $1.20 \mathrm{~A}, 1800 \mathrm{~V}$ & 3.1 & 24.5 & $9.11 \times 10^{5}$ & May 5,2010 \\
\hline
\end{tabular}

\section{NEXT Long-Duration Test Results-Metrics and Performance}

\section{Status and Test Metrics}

As of July 12, 2010, the NEXT EM3 thruster has accumulated $>30,352 \mathrm{~h}$ of operation surpassing the total operating duration of the NSTAR Extended Life Test (ELT). The NEXT thruster has processed $495 \mathrm{~kg}$ of xenon; more than double the $235 \mathrm{~kg}$ total propellant throughput processed by the DS1 flight spare in the NSTAR ELT. Figure 3 shows the propellant throughput as a function of elapsed time with reference to the NSTAR ELT and flight DS1 thruster, the requirements from various mission analyses conducted using NEXT propulsion, and the NEXT qualification level throughput of $450 \mathrm{~kg}$ (Refs. 31 to 33). The NEXT LDT demonstrated the project-level thruster throughput requirement of $450 \mathrm{~kg}$ in December 2009, achieving one of the goals of the LDT. This goal was subsequently redefined to demonstrate the thruster service life capability by operating the thruster to failure. The NEXT thruster has demonstrated a total impulse of $18.2 \mathrm{MN} \cdot \mathrm{s}$ to date; which is the highest total impulse ever demonstrated by an ion or Hall thruster. This milestone is also the highest total impulse ever demonstrated by any sub$100 \mathrm{~kW}$ electric propulsion device (Ref. 34). This exceeds the total impulse demonstrated by the 30,352 $\mathrm{h}$ NSTAR ELT in less than $1 / 3^{\text {rd }}$ the thruster operating duration, shown in Figure 4. Operating durations for all throttle table conditions and testing duty cycle (currently at 67 percent) are shown in Figure 36 and Figure 37 of the Appendix. 


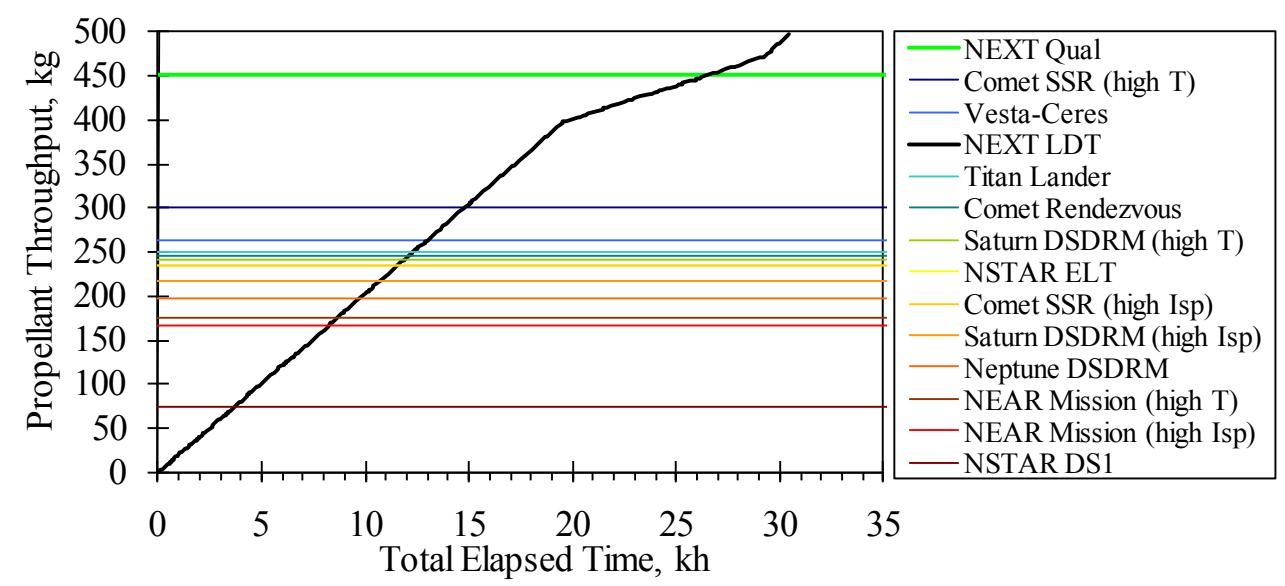

Figure 3.-NEXT LDT propellant throughput as a function of time with reference milestones. NEXT project qualification throughput $(450 \mathrm{~kg})$ was demonstrated in December 2009.

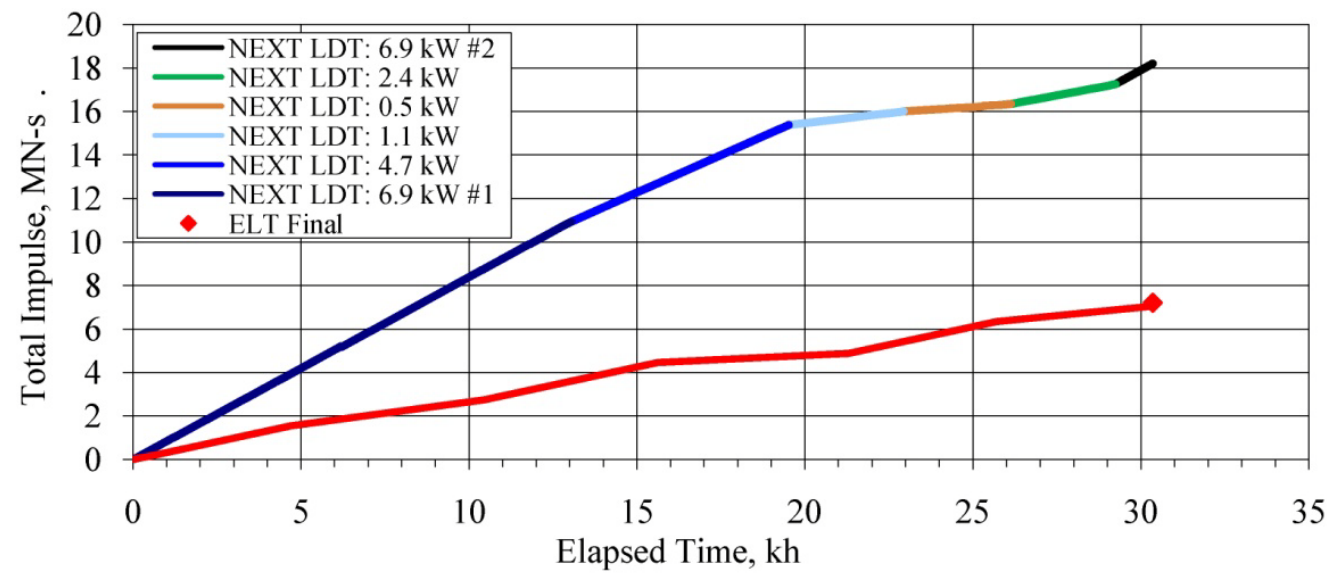

Figure 4.-NEXT LDT and NSTAR ELT total impulse demonstrated as a function of testing duration (Ref. 33).

\section{Thruster Performance}

Performance of the EM3 thruster has been steady with minimal degradation. Thruster performance measurement, calculation methodology, and assumptions are described in detail in References 20, 23, 35, and 36. A summary of key thruster performance parameters comparing beginning-of-life (BOL) performance to performance after processing $300 \mathrm{~kg}$ (lifetime requirement) and $450 \mathrm{~kg}$ (qualification150 percent lifetime requirement) were presented in Reference 37. Plots of overall thruster performance including calculated thrust, specific impulse, thrust efficiency, and input power can be found in the Figure 38 to Figure 41 of the Appendix. Recent thruster data show negligible performance degradation after 30,352 $\mathrm{h}$ of operation. Calculated thrust has remained constant while thruster input power has increased by a maximum of $30 \mathrm{~W}$ due to increasing discharge losses, less than 0.5 percent increase from BOL. Discharge losses increase due to, among other factors: accelerator grid aperture erosion that decreases the neutral density in the discharge chamber, increased thermal conductance from the discharge cathode emitter due to barium migration, and changes in surface conditions of the cathode emitter and anode collector (Ref. 21). The main degradation anticipated on a spacecraft is increasing thruster input power with thruster operating duration. Beam voltage and beam current are fixed for a given operating condition; therefore variations in thrust can only be due to variations in beam divergence, variations in neutralizer coupling voltage, variations in double-ion content of the beam, or operation with electron backstreaming. Beam profiles obtained up to $13 \mathrm{kh}$, prior to failure of Faraday probe diagnostic, have demonstrated a negligible change in the thruster 
plume divergence for any operating condition (Ref. 27). Coupling voltage and electron backstreaming margin have demonstrated little variability, which will be discussed later. A slight increase of a few percentage points in the double-ion signature of the beam has been measured by the far-field ExB probe due to increases in operating discharge voltage (Refs. 26 and 27).

At full-power, thrust and specific impulse have remained constant at values of $237 \pm 3 \mathrm{mN}$ and $4170 \pm 70 \mathrm{~s}$, respectively. The indicated uncertainty in performance values are discussed in Reference 38 . Spikes in the data in the Appendix are due to thruster shutdowns and restart events and are not reflected in the uncertainty. Slight increases in specific impulse and thrust efficiency are realized after the beginningof-test characterization due to an intentional decrease in neutralizer flow to improve overall propellant utilization efficiency. At full-power, thrust efficiency decreased from the beginning-of-test value of 0.709 to 0.706 after $13,042 \mathrm{~h}$ due to an increase in input power to the thruster from 6.83 to $6.86 \mathrm{~kW}$. This increase is a result of increasing thruster discharge losses. Trends at all operating conditions are similar: constant thrust, constant specific impulse after the neutralizer flow decrease at beginning-of-test, slightly increasing input power due to increasing discharge losses, and slightly decreasing efficiency after BOL neutralizer flow decrease due to increasing input power.

Discharge propellant utilization efficiency has been nearly constant with variations of less than 0.5 percent of measured mass flow into the thruster, due to changes in ingested mass flow as the neutralizer flow rate is changed and the vacuum pumping speed varied with the number of operational cryo-pumps during the test. Specific impulse and thrust efficiency values vary with neutralizer flow rate as expected and are shown in the Appendix. There were improvements in both parameters for most operating conditions after $300 \mathrm{~kg}$ of xenon processed due to the decreased neutralizer flow rate following the pretest characterization. However, for medium and low-power conditions, the BOL neutralizer flow rate was not sufficient to prevent plume-mode operation of the neutralizer throughout the LDT. The loss of neutralizer flow margin with propellant processed has been addressed by a design change in the dimensions of the PM neutralizer and the release of an updated throttle table (TT10) that increases the neutralizer flow rate setpoint as a function of propellant processed (Ref. 29). The increasing neutralizer flow rate results in decreases in the specific impulse and thrust efficiency values.

The maximum thruster performance variations are 2.5 percent of thrust efficiency and 4.2 percent change in specific impulse. For reference, the NSTAR ELT experienced measured degradations of less than 9 percent, for both thrust efficiency and specific impulse (Ref. 39). The modest decreases in NEXT thruster performance due to a need to increase neutralizer flow rate are well understood and expected. The increased flow rate requires additional propellant and, along with the associated decreases in thrust efficiency and specific impulse, is anticipated to have a modest impact on the spacecraft and mission trajectories.

\section{NEXT Long-Duration Test Results—Run Segments and Model Validation}

The following sections describe the mechanisms of concern that motivated operating at each of the five conditions selected for extended runtime operation in chronological order. The relevant data collected with comparison to model predictions and other ion thruster wear test data (NSTAR, NEXT, or other) will be discussed.

\section{TL40—6.9 kW Input Power-3.52 A, 1800 V}

The full input power operating was predicted to have the highest accelerator grid erosion rate of all the NEXT throttle table conditions based upon the beam current densities measured and accelerator grid potential. It was predicted, based upon other wear tests that "burn-in" of the ion optics would be observed at this operating condition. It was not expected that significant cusp erosion of the accelerator grid apertures would be observed based upon the post-test aperture diameters from NSTAR wear tests for regions of equivalent beam current densities to NEXT. However, it was expected that downstream chamfer erosion of the accelerator apertures would be observed. 


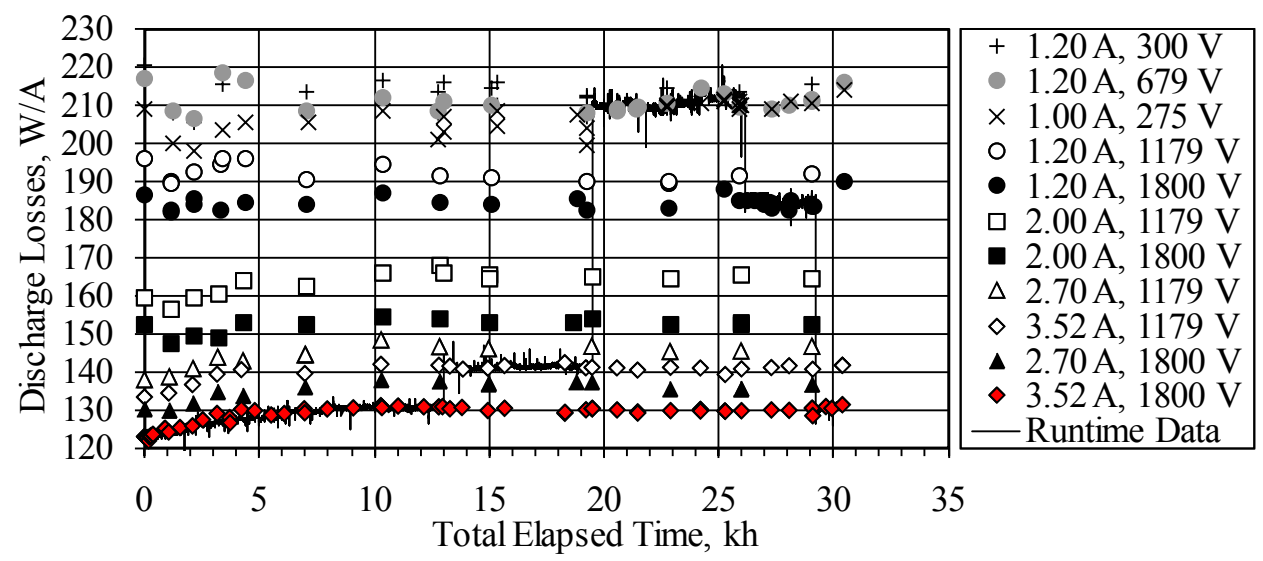

Figure 5.-NEXT LDT thruster discharge loss data as a function of time.

Most of the performance changes during the NEXT LDT have been observed during the first fullpower run segment. Thruster discharge losses with time, which are the primary cause for increasing thruster input power, are plotted in Figure 5. The pretest prediction for the anticipated increase in discharge loss at full-power was $9 \mathrm{~W} / \mathrm{A}$, which matched the LDT trend that increased from 122 to a maximum of $131 \mathrm{~W} / \mathrm{A}$ over $450 \mathrm{~kg}$ throughput. Discharge losses stabilized after several thousands of hours of operation, consistent with observed trends in accelerator aperture erosion and discharge cathode voltage and current data. The former impacts the discharge losses by decreasing neutral pressure in the discharge chamber, requiring an increase in discharge emission current to maintain a fixed beam current. The latter may be due to changes in the cathode itself: changes in emitter surface conditions, increased thermal conductance from the emitter due to barium migration, changes in the keeper geometry due to erosion, or changes in the anode surface conditions due to thin film deposits to name a few (Ref. 21). Discharge voltage and discharge current data are shown in Figure 42 and Figure 43 of the Appendix, respectively. No discharge keeper inner diameter erosion has been observed so the increasing discharge losses cannot be attributed to this phenomenon that is described in Reference 40. The NEXT LDT discharge loss increase is likely caused by the decrease in neutral pressure due to accelerator aperture chamfering, increased thermal loss from the cathode due to barium migration, and surface condition changes of the cathode emitter and anode wall. Modest increases in discharge losses, less than 6 percent of pretest values, are observed for all operating conditions. Higher discharge loss variability is observed for low power conditions that operate at higher discharge propellant utilization efficiencies where discharge loss variation is more sensitive to subtle flow variations. There have been 245 discharge cathode ignitions with an average duration of $4.5 \mathrm{~min}$ between application of the heater current and ignition. The discharge cathode ignition durations beyond the nominal 3.5 to 6 min durations have been attributed to: absorbed moisture during facility regenerations (eliminated by a 4 sccm purge during vacuum facility regenerations), thermally-induced heater open-circuits due to loss of current return path (eliminated by a hard current return on the PM design), and thermally-induced keeper shorting to cathode common (minimal impact on ignition duration) (Ref. 28).

The gradual 9 W/A, 7 percent, increase over several thousands of hours in discharge losses observed during the NEXT LDT translates into a predictable and less variable thruster performance compared to that of the NSTAR thruster. NSTAR thruster full-power discharge losses, considerably higher ( $\sim 50 \mathrm{~W} / \mathrm{A})$ than NEXT due primarily to the smaller discharge chamber, increased by 10 to 15 W/A within the first $500 \mathrm{~h}$ of operation in three separate wear tests (Refs. 41 to 43). The reduced BOL increase in discharge losses in the NEXT design is a result of a flatter NEXT beam profile; thicker accelerator grid; smallercusp, lower aperture diameter variation ion optics; and more focused beamlets at the full-power operating condition. After operating for an equivalent duration and processing $495 \mathrm{~kg}$ of propellant, the NEXT LDT full-power discharge losses increased by $9 \mathrm{~W} / \mathrm{A}$ compared to the NSTAR ELT increase of $22 \mathrm{~W} / \mathrm{A}$ after $210 \mathrm{~kg}$ (Refs. 39 and 44). 
An initial decrease in accelerator current was observed at the beginning of the test due to accelerator grid erosion - primarily restricted to outer radii accelerator grid aperture enlargement (Ref. 26). The overall trend since has been a slight decrease in observed accelerator currents as the downstream diameters of the apertures erode causing a chamfering effect, as shown in Figure 6 . The accelerator current for the NSTAR thruster on DS1 was $\sim 25$ percent less in space than the NSTAR data obtained during pre-flight measurements in a test facility operating with an operating background pressure of $3.5 \times 10^{-6}$ Torr (Refs. 31,41 , and 45). Because the NEXT LDT is operating in comparable, yet slightly higher operating background pressures, it is expected that the NEXT accelerator current in space would be reduced by $\geq 25$ percent compared to those measured in this test facility. Decreased background pressures in space reduce charge-exchange ion production thereby reducing accelerator grid erosion.

Electron backstreaming and perveance margins throughout the wear test are plotted in Figure 7 and Figure 8, respectively. Electron backstreaming limit, impingement-limited total voltage (perveance limit), and screen grid ion transparency measurement techniques are defined in Reference 46. Electron backstreaming margin has been relatively constant for all operating conditions over the entire test duration. At full-power and after completion of the throttling profile, the electron backstreaming margin was within $1 \mathrm{~V}$ of the beginning of test value, i.e., within the measurement uncertainty. In comparison, the NSTAR first failure mode was electron backstreaming, encountered during the ELT after 25,700 $\mathrm{h}$ (211 kg throughput), preventing full-power operation (Ref. 33). The NSTAR ELT full-power electron backstreaming limit increased in magnitude by $100 \mathrm{~V}$ from the beginning-of-test value to the ultimate failure after reaching the maximum power processor output of $-250 \mathrm{~V}$ (i.e., a loss of margin of $100 \mathrm{~V}$ ) (Ref. 33). The NSTAR first failure mode has been mitigated by the improved, second-generation NEXT discharge chamber and ion-optics designs.

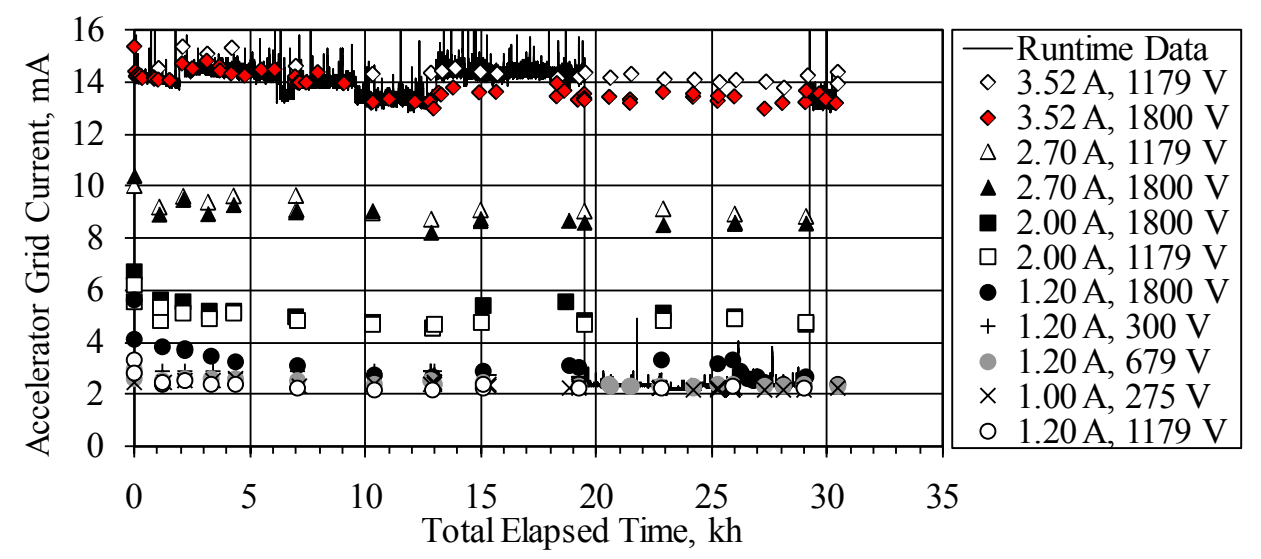

Figure 6.-NEXT LDT accelerator grid current data as a function of time.

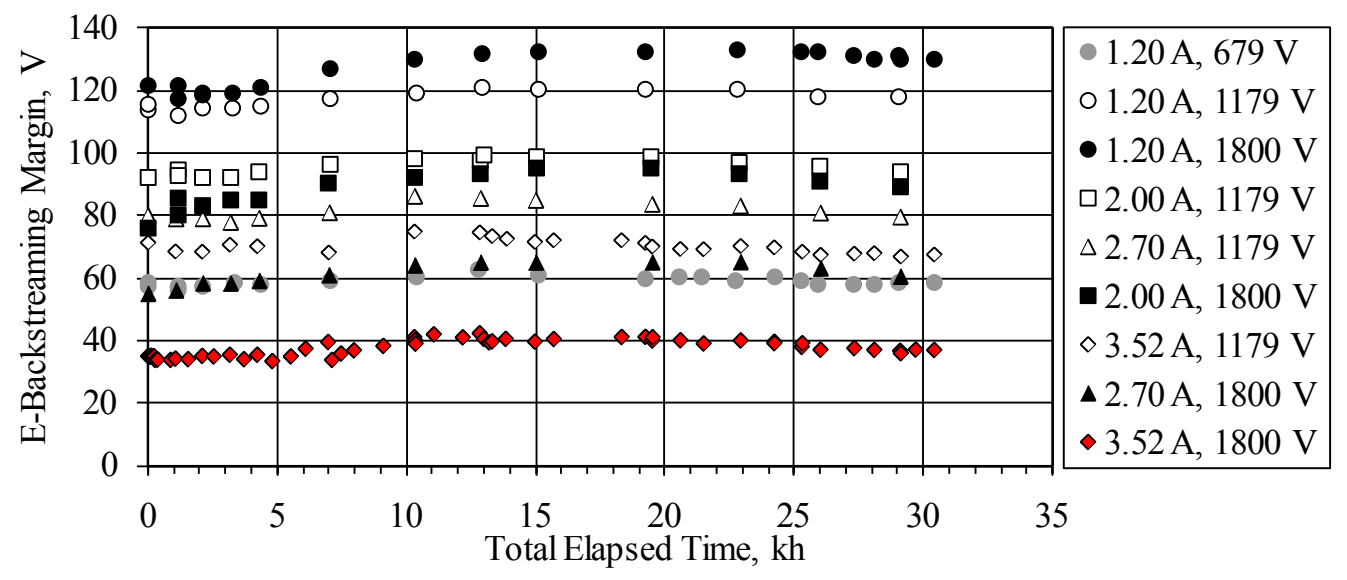

Figure 7.-NEXT LDT electron backstreaming margin data as a function of time. 


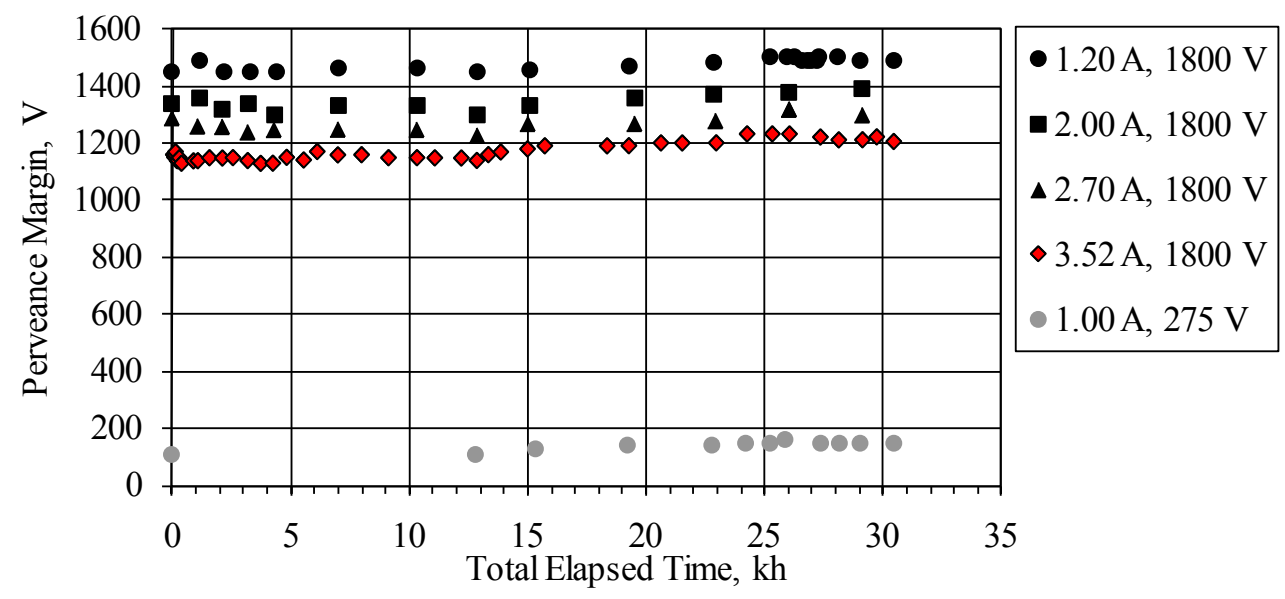

Figure 8.-NEXT LDT perveance margin data as a function of time.

Perveance margins have increased as expected due to the downstream erosion (chamfering) of the accelerator apertures, similar to that observed during the NSTAR ELT (Ref. 33). Screen grid ion transparencies exhibited a slight decrease of a few percentage points during the first $10 \mathrm{kh}$, which can be found in the Figure 44 of the Appendix. Changes in electron backstreaming limit, perveance limit, and screen grid ion transparencies are not significant enough to degrade the ion optics' performance and are less than or equal to those exhibited by the NSTAR ion optics during the $8,200 \mathrm{~h}$ wear test and NSTAR ELT (Ref. 39 and 42).

The elimination of the NSTAR first wear-out mechanism, in the NEXT design can be primarily attributed to the lack of enlargement of the accelerator grid apertures and elimination of the decreasing grid-gap of the NSTAR ion optics, illustrated in Figure 29 of the Appendix (Ref. 39 and 42). The accelerator grid aperture erosion is monitored throughout the NEXT LDT and the data shown in Figure 9. The lack of aperture barrel erosion is expected based upon the fact that the maximum beam current density for the NEXT plume is significantly less than the peak for NSTAR. Given NSTAR ELT data on accelerator grid aperture diameters measured post test and beam current density profile, it is possible to estimate a "worn-in" aperture diameter for the maximum NEXT beam current density. The NSTAR endof-test aperture diameter at a location where the beam current density is similar to the maximum NEXT beam current density is within a few percent of the NEXT EM3 BOL center aperture cusp diameter (Refs. 18, 33, and 42). From this empirical data, it is not surprising that negligible NEXT aperture diameter erosion has been observed. The detailed analysis of accelerator aperture diameter erosion can be found in Reference 18. Centerline aperture diameters were measured pre- and post-test of the NEXT EM1 and PM1R wear tests indicating negligible enlargement as well (Refs. 19, 21, and 30).

The neutralizer keeper voltage relative to neutralizer cathode common and the coupling voltage between common and the vacuum facility ground are shown in Figure 10. The keeper voltage demonstrated a slight decrease over $19.5 \mathrm{kh}$ of operation during operation at fixed emission current and flow rate (Ref. 26). The voltage decreased from 11.2 to $10.7 \mathrm{~V}$ during the first $10 \mathrm{kh}$ at full-power. This minor decrease is likely due to erosion of the neutralizer cathode orifice plate. The application of a twodimensional axisymmetric model of the plasma and neutral gas in electric propulsion hollow cathodes for the NEXT LDT neutralizer reveals that the anticipated erosion of the cathode orifice channel is sufficient to cause the observed keeper voltage drop with time (Ref. 47). While in-situ cameras image the minimum neutralizer orifice diameter, detailed erosion orifice channel profile data cannot be determined using the NEXT LDT cameras. Post-test measurements will have to be made. A decreasing nominal keeper voltage of similar magnitude was observed at full-power during the NSTAR ELT as well (Refs. 33 and 39). The observed neutralizer keeper voltage variability of $\pm 0.25 \mathrm{~V}$ for fixed operating conditions is considerably less than those observed in NSTAR ELT neutralizer cathode where the variations on the order of a volt are evident in the keeper voltage (Refs. 33 and 39). The NEXT coupling voltage was steady at $-10.2 \mathrm{~V} \pm$ 
$0.2 \mathrm{~V}$ during the first $19.5 \mathrm{kh}$. Spikes in the keeper and coupling voltages are due to thruster shutdown and restart events where steady-state conditions do not exist for the neutralizer; these can be ignored. There have been 242 neutralizer ignitions all within 6 min of application of the heater current. Typical ignition durations are between 3.5 to $4.0 \mathrm{~min}$. (Ref. 29).

The main observed NEXT LDT thruster performance degradation is the loss of neutralizer flow margin with testing duration. Relative to the NEXT technology development throttle table at the inception of the NEXT LDT, a loss in neutralizer flow margin had been observed. Flow margin has decreased, based on BOL neutralizer flow rates, for all beam current conditions over the test duration (Ref. 29). Motivated by the engineering model (EM) neutralizer low flow margin at BOL, design modifications have been incorporated into the prototype model (PM) neutralizer design yielding higher flow margin at low-power (Ref. 13). The design changes caused a slight decrease in flow margin at high emission currents where substantial BOL margin exists. The design change also results in an approximate $1 \mathrm{~V}$ increase in the magnitude of the coupling voltage (Ref. 13). A new throttle table (TT10) was released to address the observed degradation experienced during the LDT and is now the baseline throttle table for the technology program and for mission analyses (Ref. 29). The new throttle table, detailed in Reference 29 , increases the neutralizer flow rate from BOL as a function of propellant throughput processed. To determine neutralizer flow margin for a flight thruster utilizing a PM neutralizer, the LDT data was shifted based upon the difference between the pretest characterization data from the EM3 neutralizer and two PM neutralizers (Refs. 13, 20, and 29). This resulted in a shift up in flow margin of the LDT data at

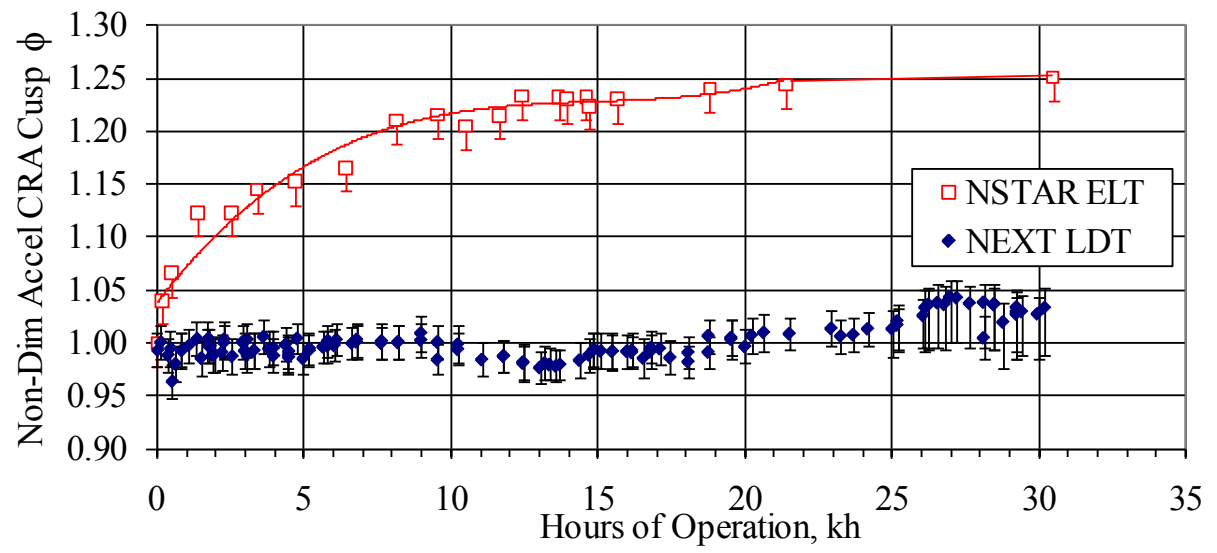

Figure 9.-Measured accelerator grid center aperture cusp diameters from NEXT LDT and NSTAR ELT as a function of test duration (Ref. 33).

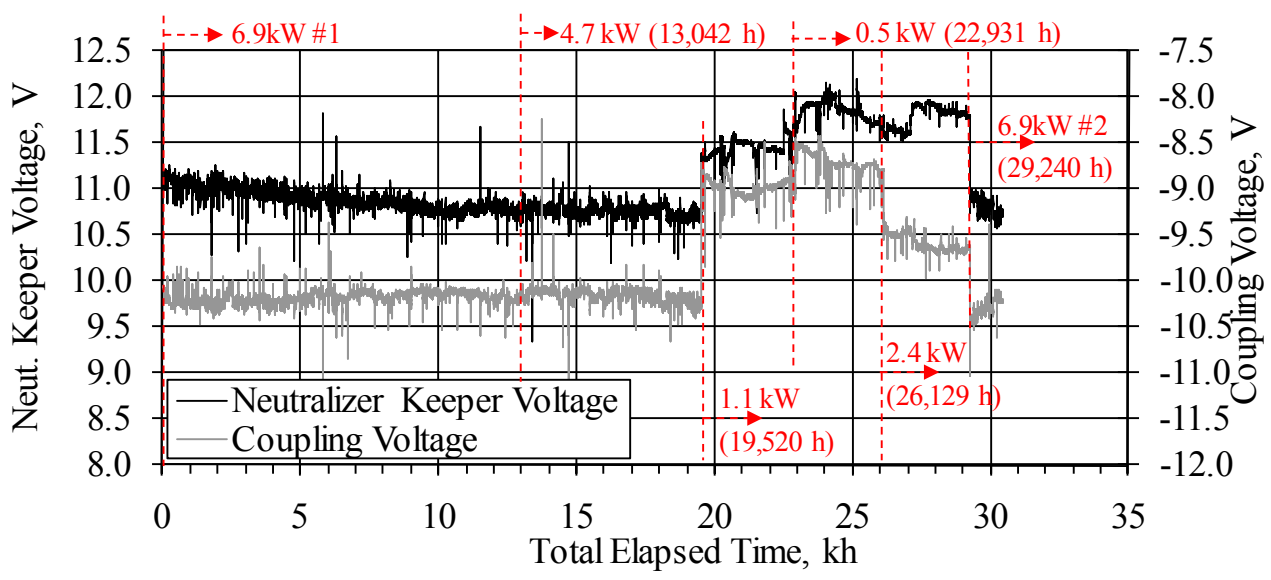

Figure 10.-NEXT LDT neutralizer keeper and coupling voltage data as a function of time. 


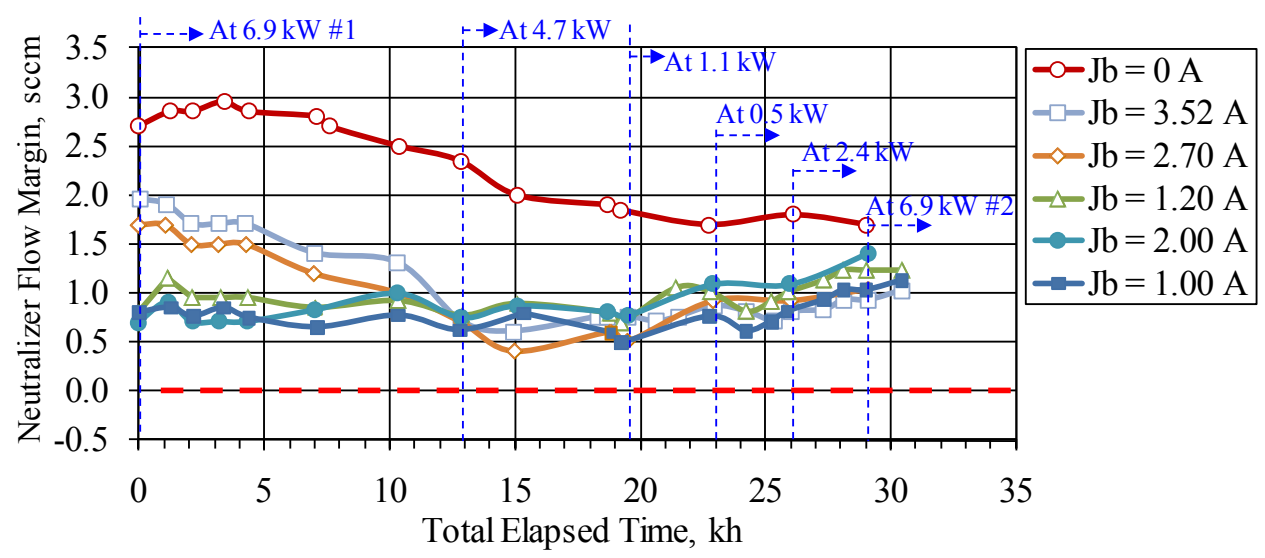

Figure 11.-Anticipated NEXT PM neutralizer flow margin data as a function of time operated in the NEXT LDT throttling profile. Measurement error is $\pm 0.1 \mathrm{sccm}$.

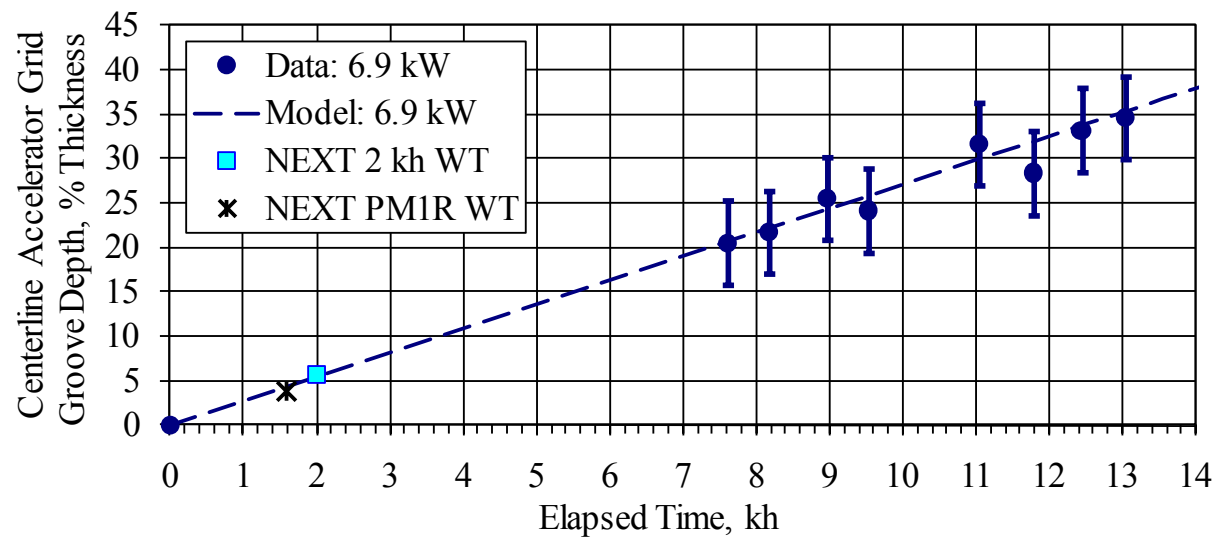

Figure 12.-NEXT centerline (highest beam current density) accelerator grid groove penetration depth for full-power as a function of operating duration.

low power of up to $0.5 \mathrm{sccm}$ and a shift down at full-power by $0.3 \mathrm{sccm}$. Figure 11 shows the predicted flow margin of a flight-like neutralizer operated in the NEXT LDT throttling profile. The flow set points, used to calculate flow margins, are from TT10. As the figure illustrates, there would have been a positive flow margin of at least $0.4 \mathrm{sccm}$ for all operating conditions throughout the NEXT LDT had it utilized a PM neutralizer and updated TT10 neutralizer flow rate inputs. The neutralizer keeper current can also be increased to provide additional flow margin.

Having demonstrated mitigation of the NSTAR first failure mode and discussed the main source of performance degradation, the main concern for full-power operation is the progression of the accelerator grid pit-and-groove erosion. The NEXT full-power operating condition is predicted to exhibit the highest accelerator grid groove erosion rate with time owing to the combination of high beam current density and magnitude of accelerator grid potential (Refs. 17 and 18). Accelerator grid groove depth has been measured via an optical diagnostic developed after $7600 \mathrm{~h}$ of operation at full-power (Ref. 48). Figure 12 illustrates the measured groove depth data. The linear trend of accelerator downstream erosion with time was also observed for the pit depth measured via laser profilometer during the NSTAR ELT (Ref. 33). The NEXT semi-empirical model predictions demonstrate excellent agreement with the LDT data and the maximum groove depth from post-test laser profilometer measurements following the NEXT EM1 2,000 $\mathrm{h}$ wear test (Refs. 19 and 30). This is extremely important because the NEXT LDT data is the major source of modeling validation, though NSTAR data were used extensively during the model development. Additionally, the insensitivity of the groove erosion rate to vacuum facility influences between VF16 and 
VF6 is supported by the groove data. The EM1 2,000 h wear test was conducted in VF6 at GRC: a $7.6 \mathrm{~m}$ diameter by $22.9 \mathrm{~m}$ long facility outfitted with 12 cryogenic pumps providing 220,000 L/s pumping speed on xenon next to the ion thruster. The backsputtered film thickness measured post-test yielded an average back-sputter rate of $1.5 \mu \mathrm{m} / \mathrm{kh}$ (Ref. 19). The full-power backsputter rate in VF16 is twice that of VF6, $3.0 \mu \mathrm{m} / \mathrm{kh}$ measured by a quartz-crystal microbalance in the same plane as the thruster exit. The groove depth data from the two tests with a factor of 2 variation in back-sputter rate indicate that pit-and-groove erosion rates in regions of high beam current density are minimally influenced by the back-sputtered carbon deposition over the indicated range. The impact of back-sputtered carbon on thruster service life will be discussed later when the thruster erosion trends are extrapolated to predict end-of-life.

\section{TL37-4.7 kW Input Power-3.52 A, 1179 V}

The $4.7 \mathrm{~kW}$ input power (TL37) operating condition presents the greatest thermal load, has the highest ratio of total emission current to discharge cathode flow, and was predicted to result in the most severe accelerator grid downstream chamfer erosion (slightly worse than full-power) in regions of moderate to high beam current density (Ref. 18). The high thermal load can impact magnetic field strength if degradation of the magnetic material occurs. There has not been an observable change in discharge characteristics that would indicate changes in the magnetic field topology. The downstream chamfer diameter of the accelerator grid aperture was increased slightly after throttling the engine from TL40 $(6.9 \mathrm{~kW})$ down to TL37 $(4.7 \mathrm{~kW})$ as measured at a radial location $16 \mathrm{~cm}$ from the thruster centerline ( $2 \mathrm{~cm}$ from the edge aperture on the accelerator grid). The data are shown in Figure 13.

The electrical shorting of the discharge keeper to cathode common was an expected event based upon the findings from the NEXT 2,000 $\mathrm{h}$ and the High Power Electric Propulsion (HiPEP) 2,000 $\mathrm{h}$ wear tests (Refs. 19 and 49). Post-test analyses measured tungsten material deposits on the upstream surface of the keeper faceplate near the orifice of 40 and $70 \mu \mathrm{m}$ thicknesses for the NEXT and HiPEP wear tests, respectively (Refs. 50 and 51). Assuming linear growth, extrapolation of these coating thicknesses for extended duration would have resulted in bridging the estimated operating gap between the NEXT LDT keeper and cathode face after an operating duration on the order of 10 to $30 \mathrm{kh}$. The short appeared in the NEXT LDT after $13.9 \mathrm{kh}$, within the bounds of the two deposition rates. The NEXT lifetime assessment also predicted a priori this shorting event and considered its impact on thruster service life (Refs. 17 and 18). Intermittent thermally-induced discharge keeper-to-common shorting appeared after 13,875 h of operation ( $833 \mathrm{~h}$ after throttling to $4.7 \mathrm{~kW}$ ). Discharge keeper voltage data are shown in Figure 14.

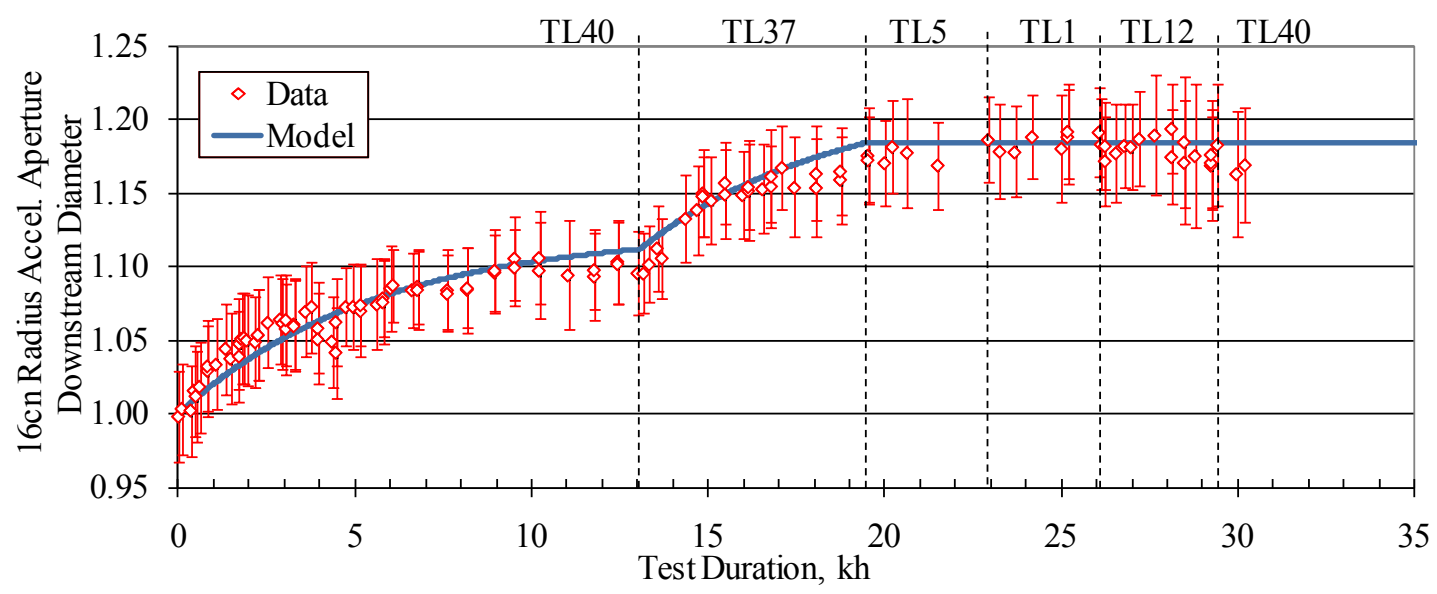

Figure 13.-NEXT LDT accelerator grid aperture downstream chamfer diameter at radial location $16 \mathrm{~cm}$ from centerline ( $2 \mathrm{~cm}$ from edge of beam extraction area) normalized to the pretest value. 


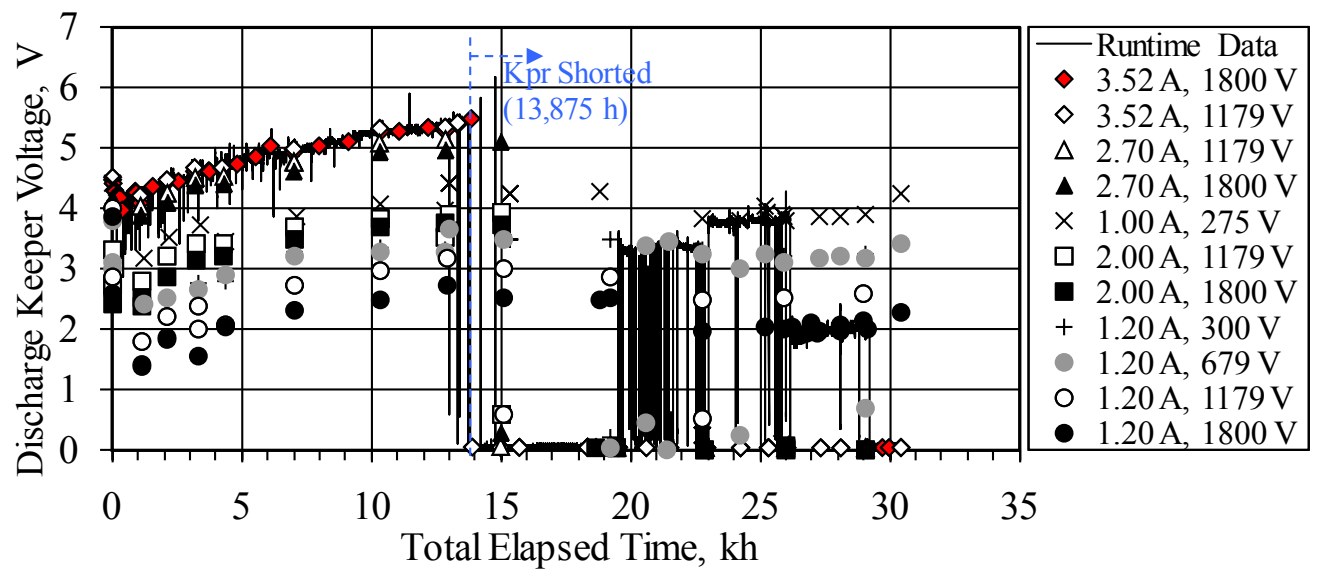

Figure 14.-NEXT LDT thruster discharge keeper voltage data as a function of time.

The shorting of the discharge keeper to cathode common is anticipated to have minimal impact on thruster operation because the keeper electrode is tied to the anode through a $1 \mathrm{k} \Omega$ resistor, which limits the current drawn to 10's of mA. The impact of the keeper short on erosion is to increase the impingement ion energy by an amount equal to the nominal keeper voltage (1 to $6 \mathrm{~V}$ ), but with the low sputter yield graphite keeper this small increase in energy results in a negligible decrease in keeper life. The shorting of the keeper has decreased the ease at which the discharge cathode is ignited and can be reignited. During a cathode ignition, the keeper electrode is at anode potential supplying a surface close to the cathode that has the full discharge power supply voltage plus igniter pulse of $750 \mathrm{~V}$ applied to it to initiate breakdown. When the keeper is shorted to the cathode common, the discharge breakdown has to take place between the cathode and the anode wall, which are much further away than the intermediate keeper electrode. Additionally, the small amount of current flowing through the keeper attenuates the igniter pulse further making ignition more difficult. The result is more variable ignition durations that tend to take longer (though not always). It has also been observed that when the keeper is shorted at operating conditions with low cathode emission current, the discharge extinguishes during a small percentage of recycle events ( $\sim 10$ percent). Shutdowns due to the discharge extinguishing are undesirable from a mission perspective, but are not new. During the NSTAR ELT, a total of 8 discharge extinguish events occurred (Ref. 33). An investigation to better understand the cause of the NEXT discharge extinguish events and a mitigation strategy has been initiated.

The $4.7 \mathrm{~kW}$ (TL37) condition also represents the highest emission current to flow rate ratio for the NEXT throttle table. The operating condition with the highest ratio of cathode emission current to cathode flow rate was the condition during which severe erosion of the discharge keeper was first observed during the NSTAR ELT, shown in Figure 15 (Ref. 33). The NEXT design, with a graphite keeper electrode, has mitigated discharge keeper erosion for realistic thruster lifetimes $(2000 \mathrm{~kg}$ throughput predicted prior to wear through of keeper) (Refs. 17 and 18). In-situ images of the keeper confirm the lack of enlargement of the keeper inner diameter, shown in Figure 16. Measured data of the discharge cathode and discharge cathode keeper orifices are shown in Figure 30. Based upon the EM1 2,000 h wear test keeper erosion, and adjusting for the difference in sputter yield when changing materials to graphite, it is estimated that the keeper thickness near mid-radius has diminished by roughly 20 percent (see Figure 33) (Refs. 18 and 19). There has not been any observed enlargement of the NEXT EM3 discharge keeper orifice or cathode orifice for any operating conditions. A high doubly-charge ion content in the discharge chamber can increase the erosion of discharge chamber surfaces and diminishes thruster performance. The doubles-tosingles signature of the thruster obtained in the far-field, shown in Figure 45 in the Appendix, indicates an increase of $\sim 2$ percentage points for all operating conditions over the duration of the test, which is consistent with the observed increase in discharge voltage and anticipated sensitivity of doubles ion content on discharge voltage (Ref. 33). 


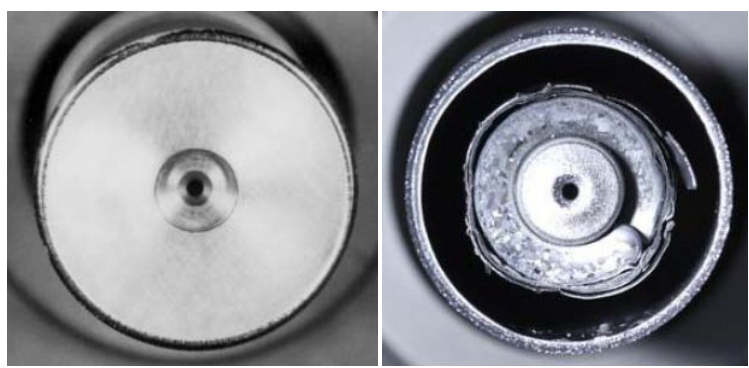

Figure 15.-NSTAR ELT discharge cathode assembly BOL (left) and after 30,352 $\mathrm{h}$ (right) (Ref. 39).
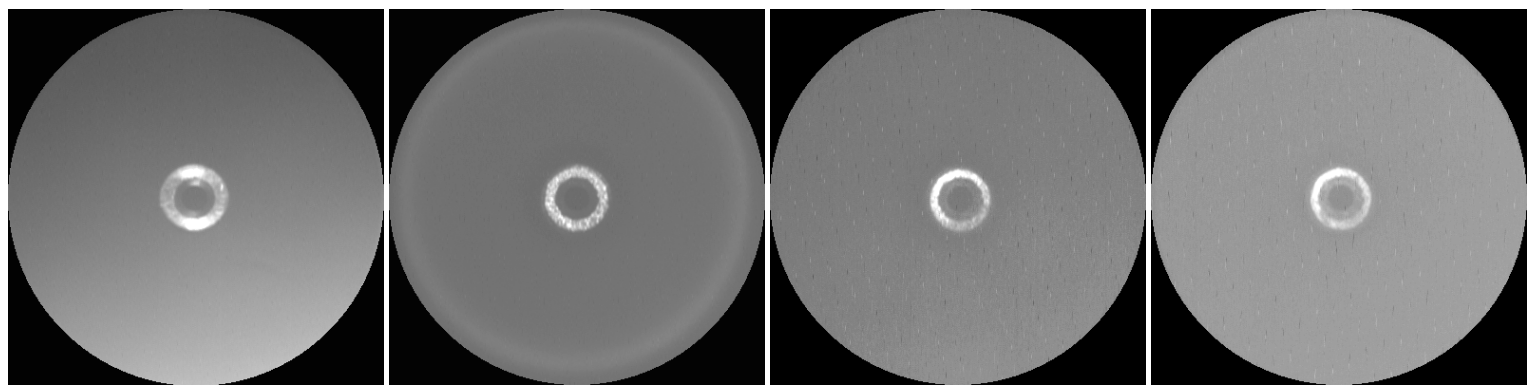

Figure 16.-NEXT LDT thruster discharge cathode assembly in-situ images as a function of time from left to right: $0,13042,19520$, and $30204 \mathrm{~h}$.
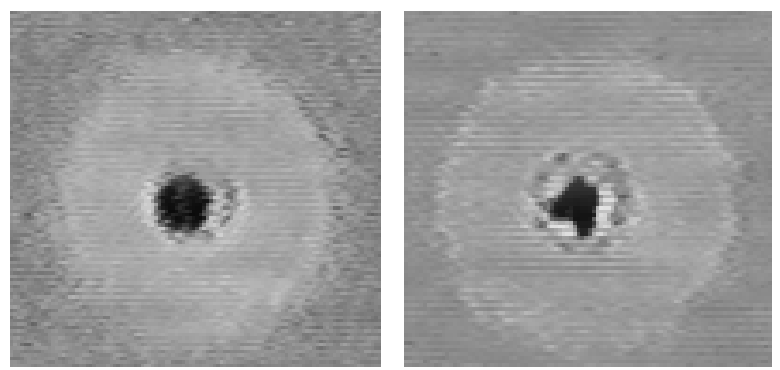

Figure 17.-NSTAR ELT neutralizer cathode orifice BOL (left) and after 21,307 h (right) (Ref. 39).

\section{TL05-1.1 kW Input Power-1.20 A, 679 V}

At low power levels (TL01 to TL12) such as TL05, the beam current set points, and hence neutralizer emission currents, are at their lowest for engine operation. At such low neutralizer emission currents, the concern for neutralizer orifice clogging is raised and is difficult to predict. The neutralizer keeper current is fixed for the entire NEXT throttle table. Within $800 \mathrm{~h}$ of throttling to $0.5 \mathrm{~kW}$, the NSTAR ELT neutralizer began to show signs of degradation as deposits began to form within the orifice, shown in Figure 17 (Ref. 39). Significant operating duration at low power levels, for which TL05 is the first of three, is required to evaluate neutralizer orifice clogging. No clogging of the neutralizer orifice has been witnessed after a total of 9,700 consecutive hours at low beam current conditions. Images of the neutralizer orifice after each of the low-power run segments demonstrates the lack of clogging in the NEXT neutralizer orifice, shown in Figure 18. No clogging of the neutralizer has been observed for any operating condition. Figure 19 illustrates the measured neutralizer orifice and keeper orifice diameters measured throughout the NEXT LDT. 

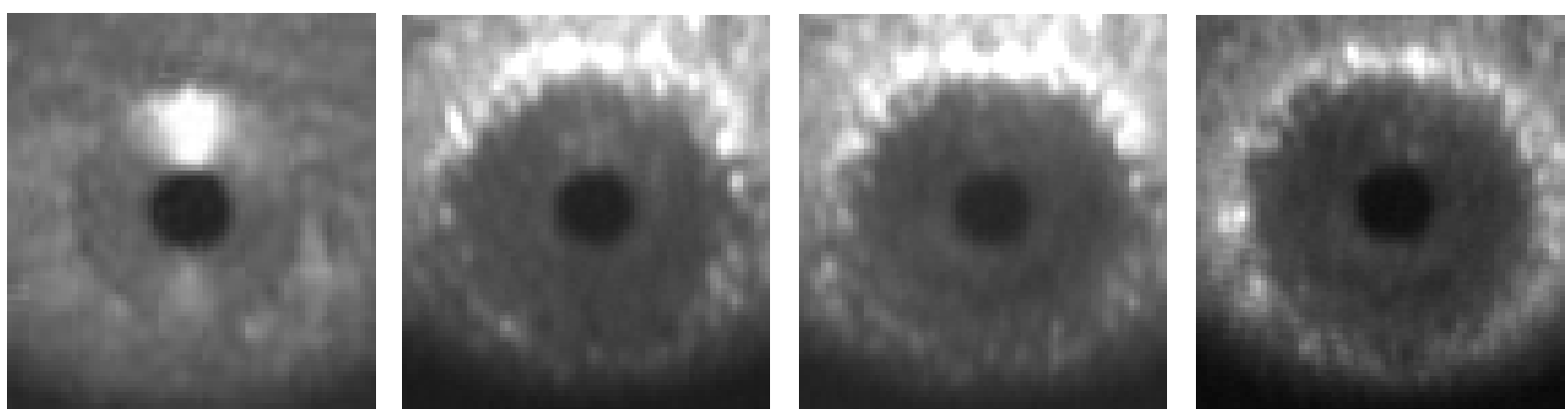

Figure 18.-NEXT LDT neutralizer cathode orifice (from left to right): BOL, 22931, 26129, and $29240 \mathrm{~h}$.

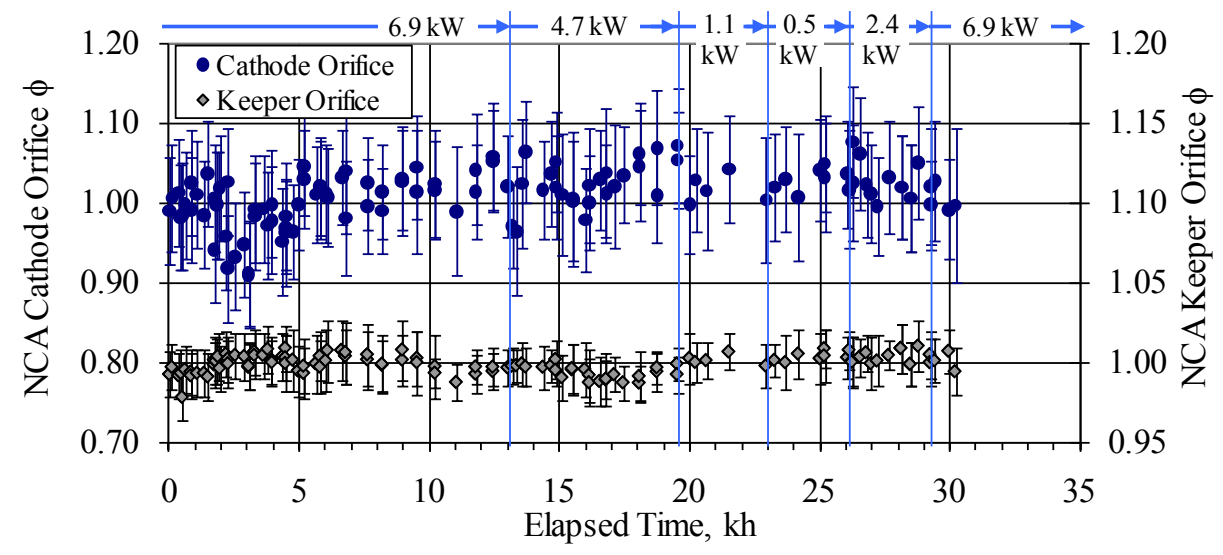

Figure 19.-NEXT LDT thruster neutralizer cathode and keeper orifice diameter data as a function of time (normalized to BOL).

\section{TL01-0.5 kW Input Power-1.00 A, 275 V}

TL01 was selected for extended operations because it represents the condition that has the lowest input power, lowest total accelerating voltage (highest magnitude), lowest thermal load, and most divergent beam. Neutralizer orifice clogging can also be a concern at TL01, but has been discussed previously. The divergence of the beam can result in excessive erosion of the neutralizer cathode assembly. Due to the high magnitude of the accelerator grid voltage and low flow rates, this is the condition with the highest accelerator grid downstream erosion as a function of propellant throughput. The thruster can operate for substantial duration, over $60 \mathrm{kh}$, at this operating condition with the TT10 input of $-350 \mathrm{~V}$ for accelerator grid voltage (in previous throttle tables and in the service life publication the model calculations were $45 \mathrm{kh}$ for an accelerator grid voltage of $-500 \mathrm{~V}$ ) (Ref. 18). The centerline accelerator groove erosion depth as a function of test duration during TL01 $(0.5 \mathrm{~kW})$ run segment is shown in Figure 20.

At the lowest input power operating condition, the R-ratio (i.e., the ratio of beam voltage to total voltage) is the lowest of all NEXT throttle table conditions. With such a low R-ratio, the divergence of the high-energy ion beam is increased. Erosion of the neutralizer keeper tube due to impingement of the ion beam has been measured in previous NSTAR and NEXT wear tests (Refs. 19 and 39). The neutralizer keeper faceplate weld at the 6 o'clock location (i.e., facing the ion beam) is being monitored and measured data shown in Figure 21. The NEXT LDT utilizes PM ion optics with a beam extraction diameter of $36 \mathrm{~cm}$ compared to the EM ion optics $40 \mathrm{~cm}$ diameter. The reduction in beam area was motivated by the substantial erosion of the accelerator apertures with the last $2 \mathrm{~cm}$ radially of the extraction region. Besides the reduction of this direct impingement erosion, the masked down PM ion 


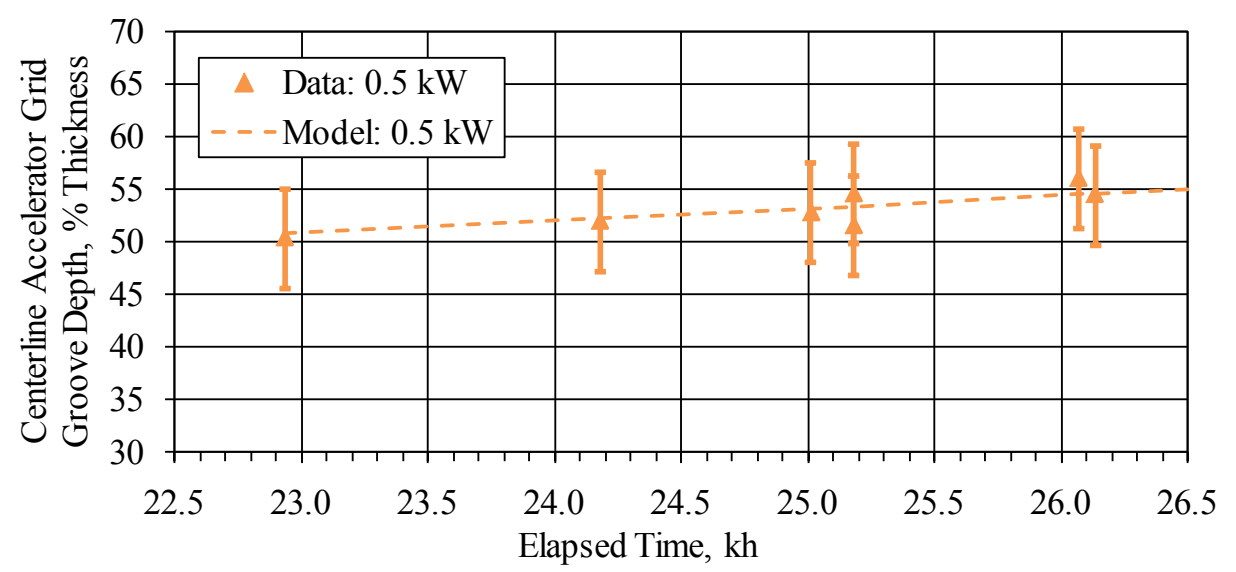

Figure 20.-NEXT centerline accelerator grid groove penetration depth for TL01 $(0.5 \mathrm{~kW})$ as a function of operating duration.

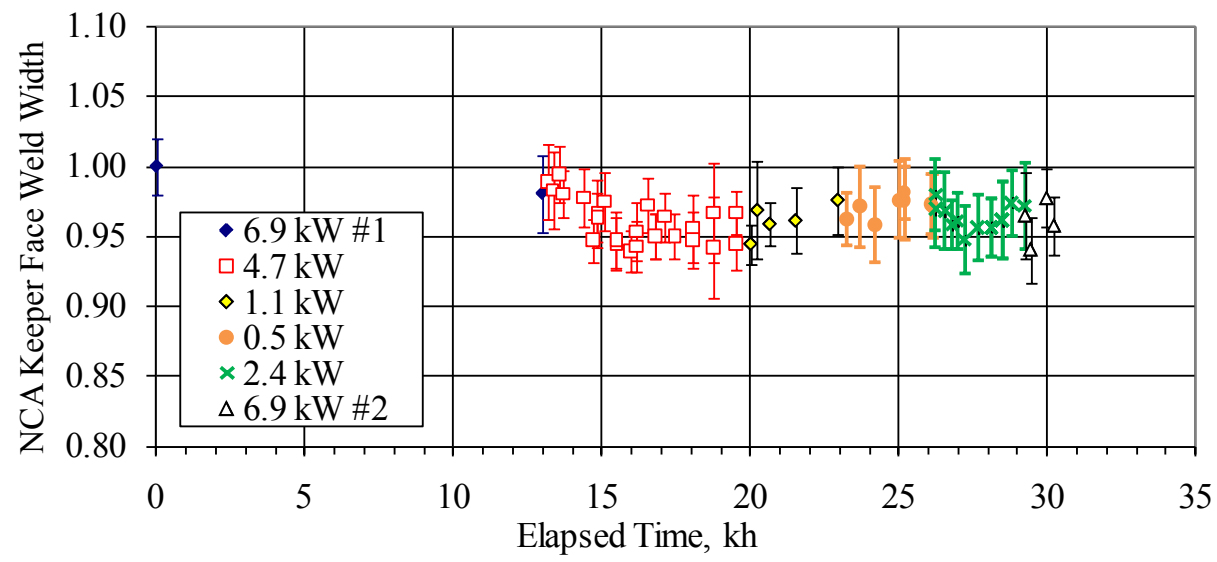

Figure 21.-NEXT LDT neutralizer keeper faceplate weld thickness at 6 o'clock position (facing ion beam) data as a function of time normalized to pretest measurements.

optics have reduced the erosion of the neutralizer tip by reducing the impingement of ions emitted at large angles from the outer edge of the thruster. This reduction in direct neutralizer impingement has been modeled by the Electric Propulsion Interactions Code (EPIC) for 36 and $40 \mathrm{~cm}$ beam extraction diameter NEXT ion optics operating at full-power (Ref. 52). The model results indicate that when the NEXT accelerator grid is masked down to $36 \mathrm{~cm}$ beam extraction diameter, there is no direct impingement to the neutralizer and only elastically scattered particles are responsible for neutralizer erosion (Ref. 52). Images of the neutralizer cathode assembly after each run segment can be seen in Figure 22 with the keeper tube facing the ion beam toward the bottom of the images. Profile images taken from a viewport on the side of the vacuum chamber show some discoloration near the front of the keeper tube facing the ion beam, but no measureable loss of thickness can be measured from the images, shown in Figure 23. 

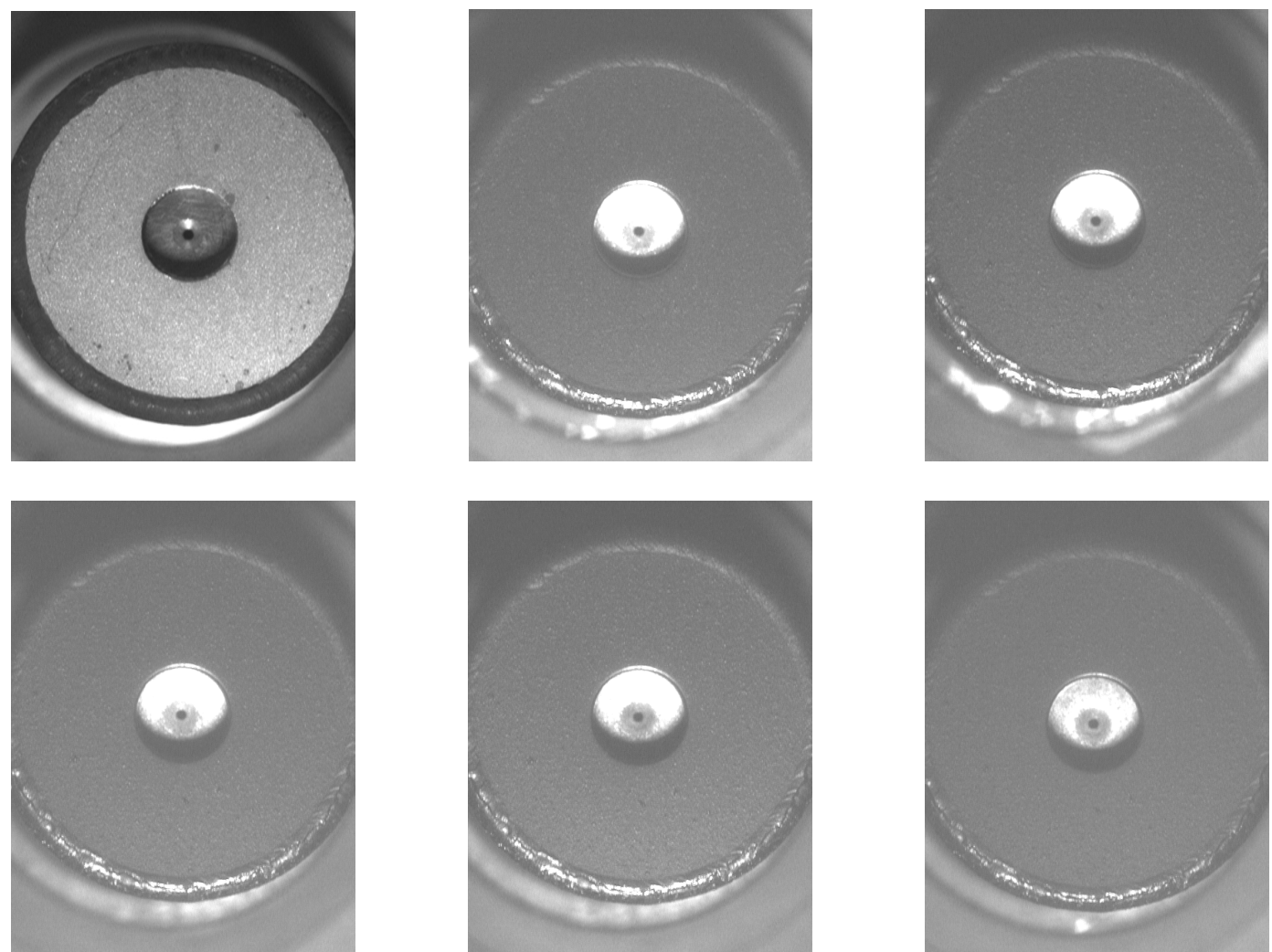

Figure 22.-NEXT LDT neutralizer cathode with keeper tube facing ion beam at 6 o'clock position after each run segment from left to right: (top) BOL, 13042 and $19520 \mathrm{~h}$, (bottom) 22931, 26129, and $29240 \mathrm{~h}$.
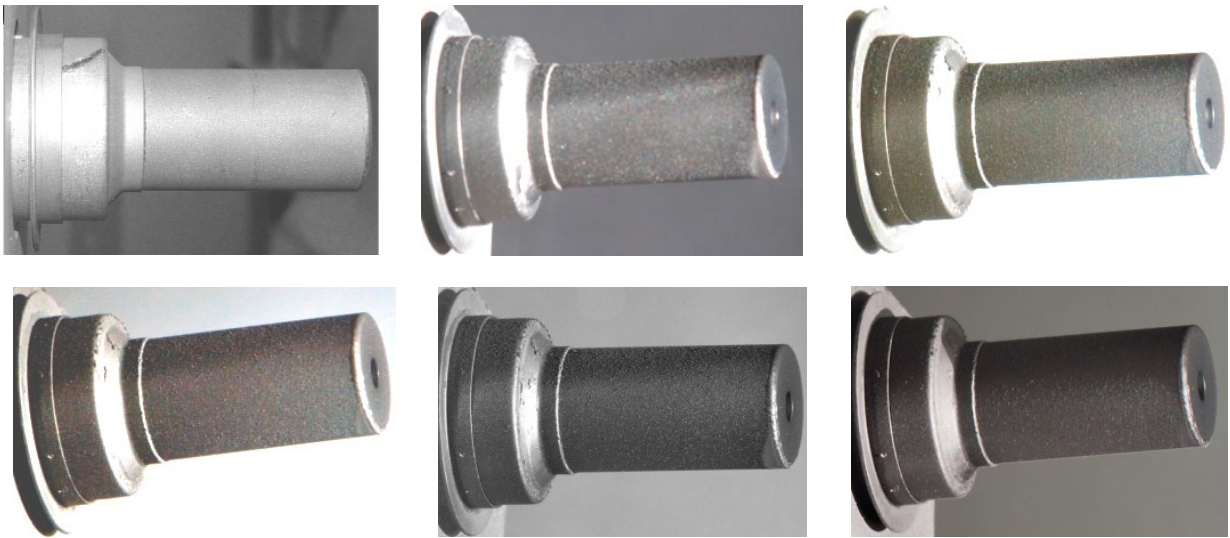

Figure 23.-NEXT LDT neutralizer keeper tube profile images as a function of time from left to right: (top) 0, 13042, and $19520 \mathrm{~h}$, (bottom) 22931, 26129, and $29240 \mathrm{~h}$.

\section{TL12-2.4 kW Input Power-1.20 A, 1800 V}

Over-focusing erosion at the outer edge apertures on the accelerator grid is the main concern for TL12 operation where it is most severe. Hexagonal star-shaped erosion resulting from over-focusing at the outer accelerator grid apertures in regions of low beam current densities was observed during the NEXT EM1 2,000 h wear test (Ref. 19). The concern for this over-focused erosion is not structural failure of the grid, but an unclearable grid electrical short from redeposited and spalled sputter material from this erosion. The reduction of the beam extraction area from 40 to $36 \mathrm{~cm}$ was intended to, in part, address this 
over-focused erosion. The cross-over direct impingement was modeled using the MICHELLE code for both EM and PM ion optics concluding that the masked down PM ion optics would mitigate cross-over impingement for all operating conditions other than TL12 (Ref. 53). There is no way to eliminate the asymmetric erosion observed at the edge apertures. TL12 is the most extreme combination of high total voltage and low beam current density, i.e., the worst case for cross-over direct impingement. Measured estimates of the PM ion optics' operating grid gap for the LDT run segments, a model input, are shown in Figure 46 of the Appendix.

The outer-radius accelerator grid apertures have been monitored by the in-situ cameras as the crossover impingement erodes the downstream surface. The erosion is asymmetric due to the asymmetric electric field inside the aperture as a result of the edge aperture location (i.e., the typical six neighboring apertures are not all there). Photographs of one representative outer-radius accelerator grid aperture are shown in Figure 24 at BOL, after full-power operation segment one, and after operation at TL12. As expected, the aperture downstream geometry has eroded beyond that experienced after full-power operation. The area of the outer-radius apertures with three neighboring apertures is shown in Figure 25. The data illustrate the erosion at full-power reaching a final geometry after $\sim 2 \mathrm{kh}$ then remaining constant (slight decrease due to back-sputtered carbon filling in "ear" edges) until TL12 operation. The model prediction for ORA erosion is in good agreement up to TL12. At TL12 the model is overpredicting the erosion, which was expected since the model approach was a conservative one. The discrepancy between the model and data can also be due to uncertainty in the beamlet current density at the outer-radius aperture location. This input to the model has been estimated from beam current density data obtained downstream of EM3 during the NEXT LDT. Improved measurement of the beamlet current density at the outer-radius aperture location for the EM3 thruster could account for the modeling discrepancy.

The masking down of the ion optics from 40 to $36 \mathrm{~cm}$ was predicted to mitigate crossover erosion for all operating conditions except for TL12, which would experience direct impingement only at the outer apertures of the perforated region (Ref. 53). Images taken during the NEXT LDT following the TL12 operating segment are shown in Figure 26. The images show hexagonal downstream chamfer erosion of the accelerator grid for the first symmetric outer aperture and the aperture $2 \mathrm{~cm}$ in from the outer radius edge. The erosion is restricted to the downstream chamfer as opposed to the observed hexagonal cusp and chamfer erosion at a location $1.6 \mathrm{~cm}$ from the outer edge from the NEXT 2,000 $\mathrm{h}$ wear test after fullpower operation (Ref. 19 and 30). The TL12 operation is considerably worse for the NEXT PM ion optics cross-over erosion than the TL40 operation for the NEXT EM optics in the 2,000 $\mathrm{h}$ wear test, yet less cross-over erosion is observed. This result confirms the findings from the ion optics modeling and the decision to mask down the ion optics to mitigate a possible thruster failure mode.

It is important for evaluation of the outer-radius erosion at TL12 that the accelerator grid apertures reach their final geometry. This allows the redeposition of sputtered material to assess the likelihood of spalling of this material causing an electrical short of between grids of the ion optics. In addition to the camera images of the accelerator grid apertures, perveance and accelerator grid current data at TL12 indicate the approach of the outer-edge erosion to a final geometry. The accelerator grid currents obtained during perveance measurements and during thruster operation are shown in Figure 27 and Figure 28, respectively. The perveance data show the reduction of the wing towards high total voltage, where the cross-over impingement is significant, decreasing with operating duration at TL12. After approximately 1,000 $\mathrm{h}$ of operation at TL12, the perveance data indicate negligible change in the perveance characteristics. The accelerator grid current data asymptotes to a final value after roughly $1,500 \mathrm{~h}$ of operation. The outer radius images indicate reaching the final geometry within 1,500 to $2,000 \mathrm{~h}$ of operation. In all cases, 1,000 to 2,000 h of operation are demonstrated beyond the end of outer-edge erosion due to cross-over impingement. There has been no indication of electrical shorting of the ion optics or other thruster components as a result of TL12 operation. The thruster recycle rate has also remained constant throughput TL12 operation. 

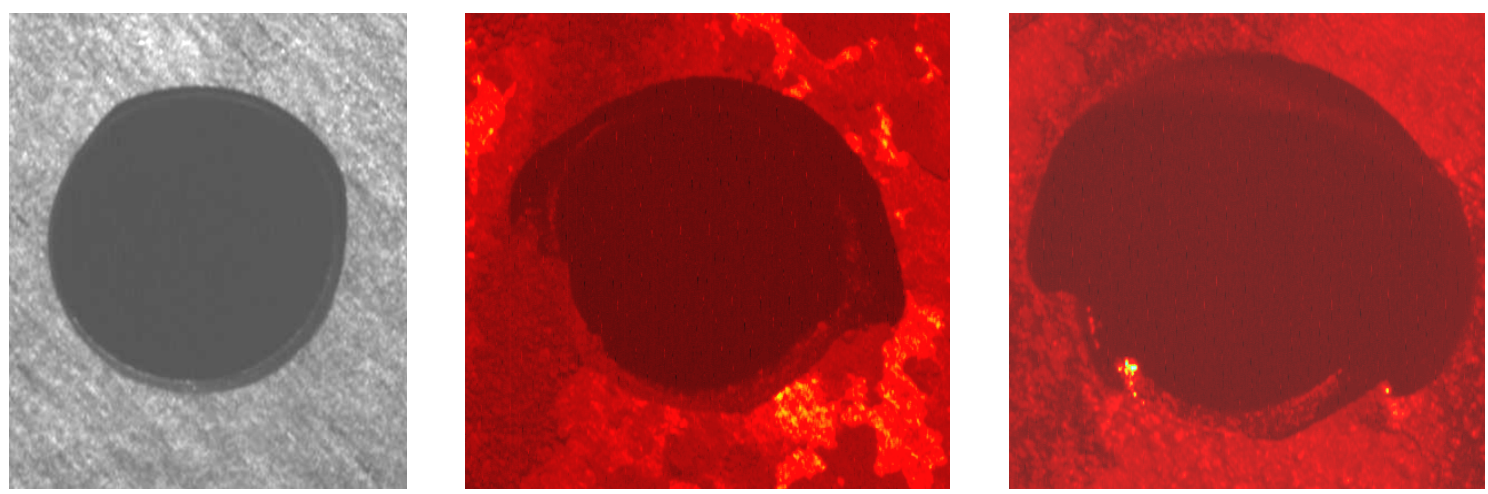

Figure 24.-NEXT LDT accelerator outer-radius three-neighbor apertures from left to right: 0, 13042, and 29240 h.

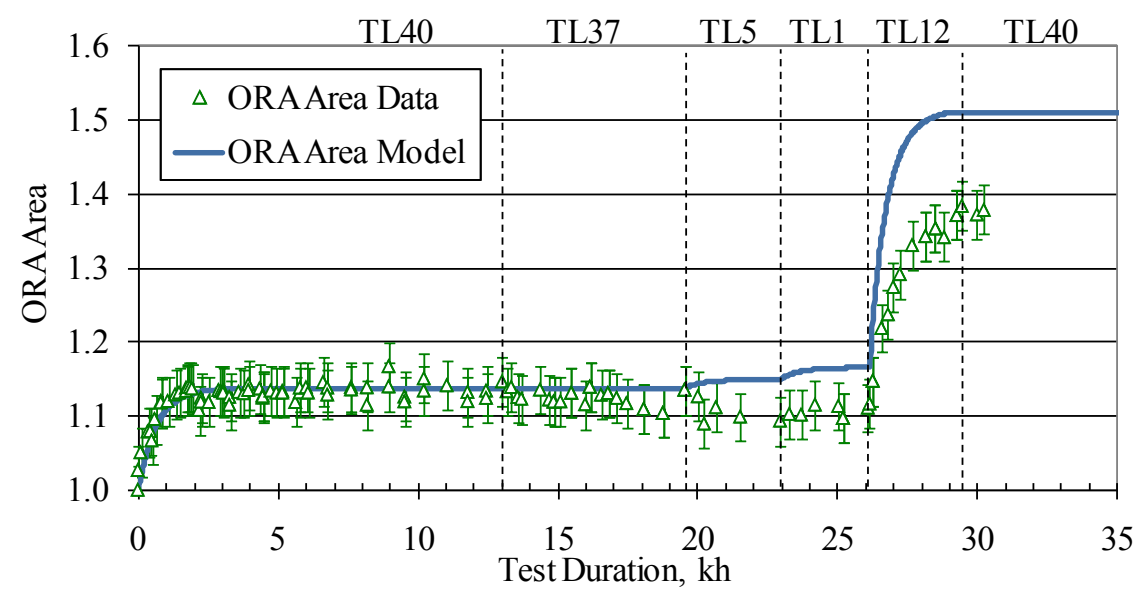

Figure 25.-NEXT LDT outer-radius downstream chamfer erosion area data as a function of time normalized to BOL aperture downstream area.
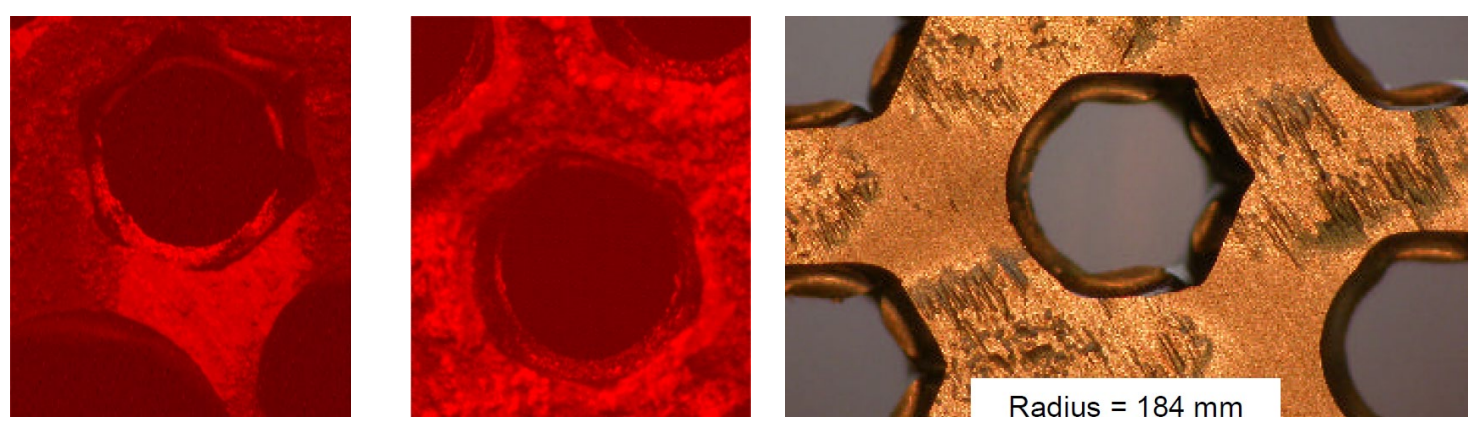

Figure 26.-NEXT over-focusing direct-impingement erosion from left to right: LDT PM optics at first sixneighbor outer-radius location, LDT PM optics $2 \mathrm{~cm}$ in from outer-radius edge, $2000 \mathrm{~h}$ wear test EM optics $1.6 \mathrm{~cm}$ in from outer-radius edge. 


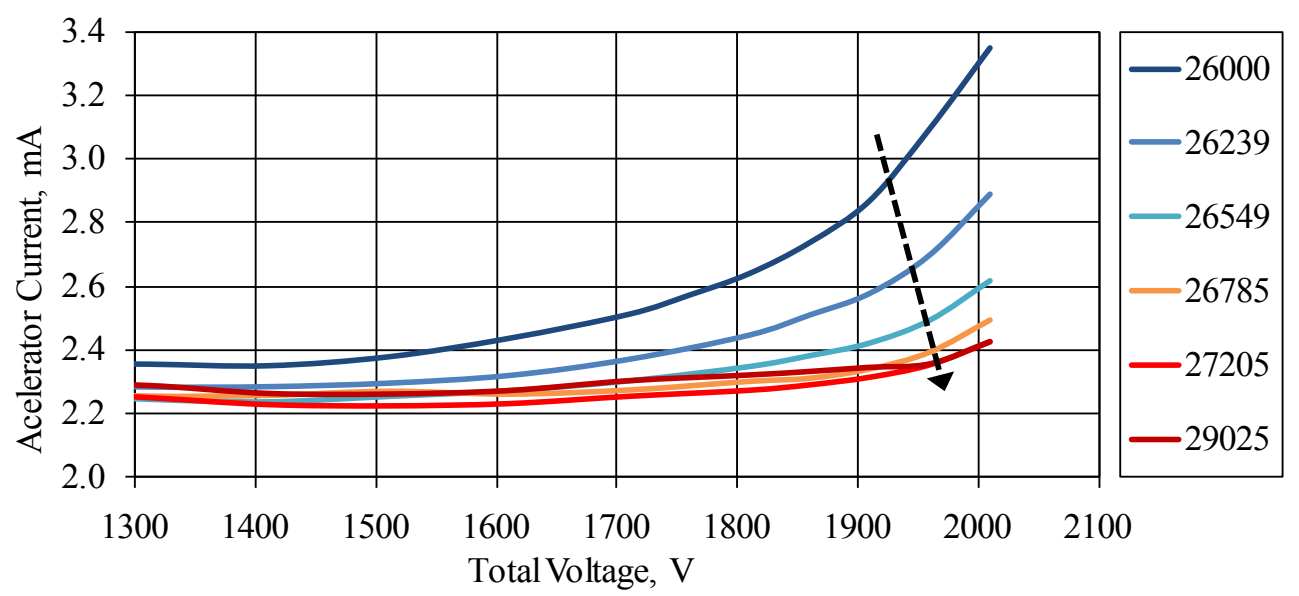

Figure 27.-NEXT LDT accelerator grid current as a function of total accelerating voltage for TL12 at various thruster operating durations.

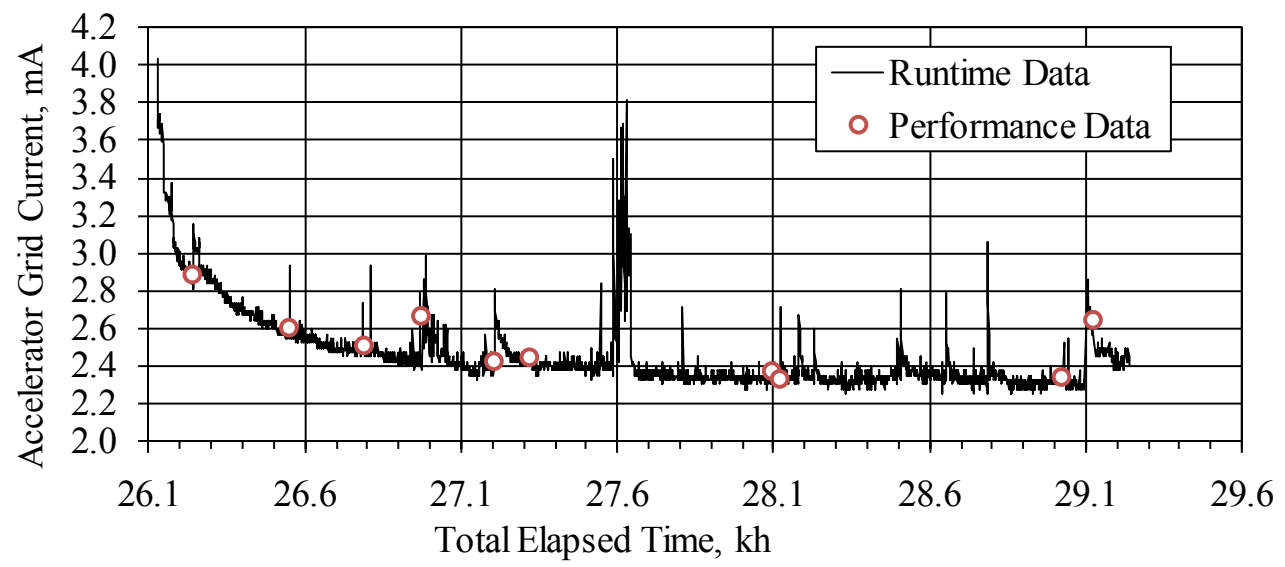

Figure 28.-NEXT LDT accelerator grid current data at TL12 as a function of time.

\section{NEXT Long-Duration Test Results-NSTAR Issue Mitigation}

The NEXT thruster has successfully built upon the NSTAR development and flight programs. The NEXT thruster design has successfully mitigated several issues and wear out modes encountered during the NSTAR thruster development and flight programs. Upon completion of the 30,352 h of operation for the NSTAR ELT: the thruster could no longer operate at full-power due to the inability to prevent electron backstreaming; the keeper electrode of the discharge cathode was completely eroded away leading to erosion of the heater coil, radiation shielding, and cathode orifice plate; and charge-exchange erosion had penetrated the accelerator grid thickness at the pits in the hexagonal pit-and-groove pattern. These findings led to additional thruster failure modes for the NSTAR thruster relating to the erosion processes as described in the NSTAR ELT report (Refs. 33 and 39). With the NEXT thruster, which attempted to mitigate these issues, it has been the case that after $30,352 \mathrm{~h}$ of operation the NEXT LDT can operate at any condition on the throttle table, has negligible discharge keeper erosion, and pit-andgroove erosion depths have penetrated less than 60 percent of the accelerator groove thickness. Additionally, many of the undesirable issues observed during the NSTAR wear tests have been addressed by the NEXT design. 


\section{NSTAR First Failure Mode-Electron Backstreaming}

The first failure mode encountered during the NSTAR ELT was the inability to prevent electron backstreaming. Enlargement of the accelerator grid apertures and the measured decrease in ion optic's cold grid-gap contributed to the inability to prevent neutralizer electrons from backstreaming into the discharge chamber primarily near the grid center. To reduce accelerator aperture erosion, the NEXT thruster design has reduced aperture enlargement by improving beam flatness thereby decreasing the maximum beam current density. The NEXT peak beam current density varies from roughly 1.5 to $4.2 \mathrm{~mA} / \mathrm{cm}^{2}$ over the NEXT throttle table (Refs. 13 and 27). Measurements from the NEXT LDT indicate a peak beam current density at full-power varying of $4.17 \mathrm{~mA} / \mathrm{cm}^{2}$ corresponding to a beam flatness parameter of 84 percent compared to the $5.56 \mathrm{~mA} / \mathrm{cm}^{2}$ and 50 percent NSTAR values measured during the NSTAR ELT at full-power (Refs. 13, 27, and 54). Plotting the post-test accelerator aperture minimum diameter versus local perveance, based upon beam current density data from the NSTAR 8,200 h wear test, provides input for a first-order estimate of the NEXT centerline full-power aperture erosion (Refs. 18 and 42). Given the local perveance for the NEXT LDT at full-power based upon beam current density profiles indicates a post-test minimum aperture diameter that is equal to the NEXT LDT PM ion optics pretest measured centerline cusp diameter. As a result one would not expect to observe any change in the accelerator grid aperture minimum diameter (i.e., cusp) for the NEXT LDT excluding the extreme outerradius locations where cross-over impingement is important. This is confirmed by the in-situ center-radius aperture data shown in Figure 9 and by data at other radial locations across the thruster face (Ref. 27).

In addition to the enlargement of accelerator grid apertures, the NSTAR wear tests noted a decrease in the measured pre- and post-test cold grid-gap of the ion optics. Decreases in grid-gap cause an increase the electric field between the grids resulting in reduced electron backstreaming margin and increased arcing between the grids. Pre- and post-test grid-gap measurements from the NSTAR ELT and 8,200 $\mathrm{h}$ wear test indicated 30 and 12 percent reduction in the cold grid-gap, respectively (Refs. 33, 39, and 42). It is not known how the grid-gap varied over the course of the tests because no data are available. Analysis of electron backstreaming data indicates the grid-gap change probably occurred slowly over the duration of the test (Ref. 33). A decrease in the cold grid-gap of 7 percent was also observed following the NEXT 2,000 $\mathrm{h}$ wear test, which utilized EM ion optics. To address this undesirable change, the PM ion optics assembly and mounting scheme were modified from the EM design specifically to address and eliminate the observed decreasing cold grid-gap with thruster operation. A camera images the centerline cold gridgap periodically throughout the LDT. Within the measurement uncertainty, there has been no observed change in the NEXT LDT cold grid-gap, shown in Figure 29. The EM3 thruster utilizes PM ion optics.

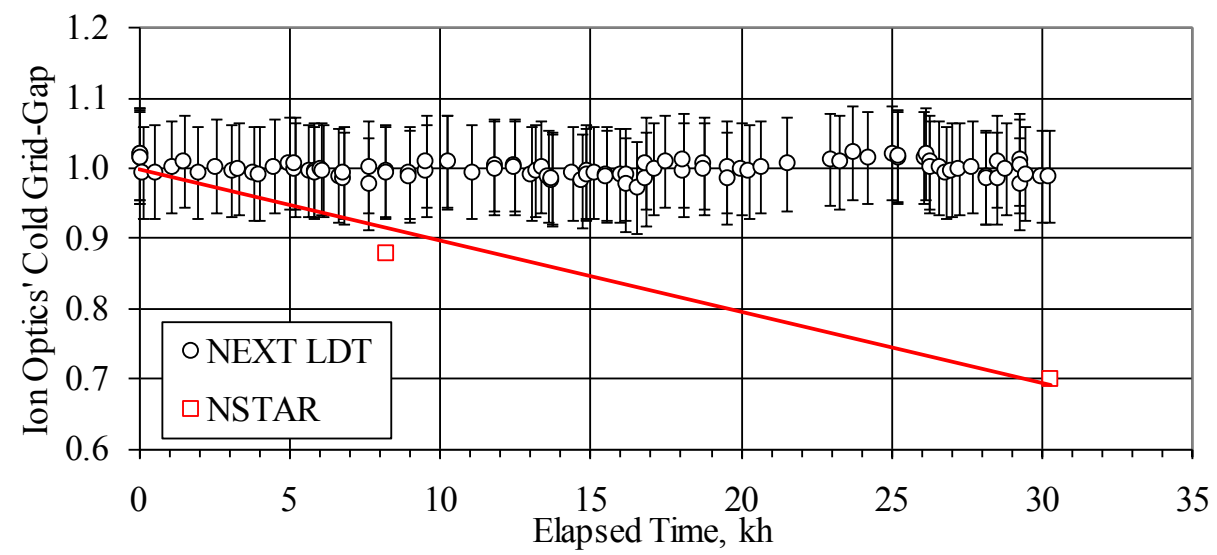

Figure 29.-NEXT LDT and NSTAR cold ion optics' grid-gap, normalized to pretest measurements, as a function of testing duration (Ref. 39 and 42). 
The improved beam flatness of the NEXT design and elimination of the changing cold grid-gap have successfully addressed the first failure mode encountered in the NSTAR design. The electron backstreaming margin has remained constant over the test duration, shown in Figure 7 . The result of these changes is to push the thruster wear-out mode to another mechanism that progresses very slowly, thus resulting in substantial improvement in thruster service life capability.

\section{NSTAR Discharge Cathode Assembly Erosion}

Severe erosion of the discharge cathode assembly was observed during the NSTAR ELT. After $15,000 \mathrm{~h}$ of operation, the keeper electrode eroded sufficiently to fully expose the cathode heater, radiation shielding, and cathode orifice plate. Post-test examination of the NSTAR ELT discharge cathode revealed complete removal of the cathode orifice plate weld joint. The orifice plate was only held on the cathode tube by a 20 to $50 \mu \mathrm{m}$ area of thermally induced fusion between the cathode tube and orifice plate (Ref. 39). Because of the severe NSTAR ELT discharge cathode erosion, additional potential failure modes were uncovered including cathode failure due to cathode heater erosion and unclearable grid-to-grid short or rogue hole formation due to flaking of the discharge cathode radiation shielding (Ref. 39). Figure 16 shows the discharge cathode at various testing durations during the NEXT LDT. The NEXT discharge cathode faceplate has become slightly textured, but the discharge cathode orifice and keeper orifice diameters have not changed within the measurement error, as shown in Figure 30, normalized by the beginning-of-test values. There has not been a noticeable change in any of the discharge cathode assembly orifices.

During the NSTAR ELT, the keeper electrode was completely eroded away, exposing the discharge cathode and heater (Ref. 55). The NSTAR ELT keeper erosion was characterized by a widening of the keeper orifice in contrast to the NEXT 2,000 $\mathrm{h}$ and NSTAR 8,200 $\mathrm{h}$ wear tests, in which the most severe erosion was focused towards the mid-radius of the keeper faceplate (Refs. 19, 42, and 56). The primary function of the discharge cathode keeper is to protect the discharge cathode from excessive sputter erosion. The EM3 keeper material was changed to graphite, which has a sputter yield an order of magnitude lower than that of the molybdenum at $50 \mathrm{eV}$ (Ref. 57). While the LDT results confirm that no enlargement of the keeper orifice has occurred, the erosion of the downstream face of the keeper is not measured in-situ. Discharge cathode keeper downstream surfaces from the NSTAR 8,200 $\mathrm{h}$ and NEXT $2,000 \mathrm{~h}$ wear tests were qualitatively similar with the deepest erosion at a radii of 55 to 60 percent and 40 percent of the total keeper radius, respectively (Refs. 19, 42, and 56). Scaling the NEXT 2,000 h wear test molybdenum discharge keeper erosion rate (depth of 17 percent of the keeper thickness after test) with the decrease in sputter yield of graphite compared to molybdenum gives a conservative estimate of wear through of the keeper after $>100 \mathrm{kh}$ at full-power ( $>2000 \mathrm{~kg})($ Refs. 17, 18, 56 to 58).

Shorting of the discharge keeper to common was observed during the NSTAR ELT and coincided with the onset of the anomalous discharge cathode assembly erosion (Ref. 39). It was anticipated based upon the findings of the NEXT EM1 and HiPEP 2,000 $\mathrm{h}$ wear tests that a similar shorting event would occur during the NEXT LDT after an operating duration on the order of 10 to $30 \mathrm{kh}$ (Refs. 17 to 19, and 51). The short appeared in the NEXT LDT after $13.9 \mathrm{kh}$ for mid- to high-emission currents, but has not altered the observed lack of discharge keeper erosion. The NEXT lifetime assessment also predicted a priori this shorting event and considered its impact on thruster service life (Ref. 18 and 59). Both the pretest service life assessment and erosion measurements indicate a negligible increase in the keeper electrode due to the presence of a keeper to cathode common short mainly due to the low sputter yield of the graphite keeper. 


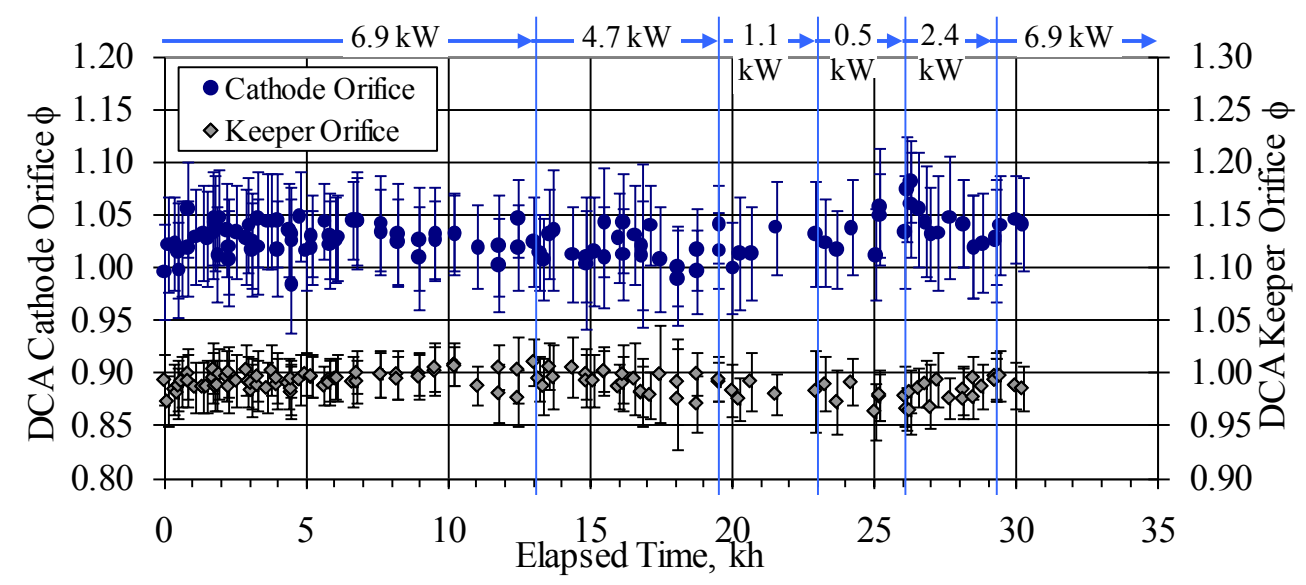

Figure 30.-NEXT LDT discharge cathode and keeper orifice diameters normalized to BOL. Short between keeper and cathode observed for high emission current after $13,875 \mathrm{~h}$ of operation.

\section{NSTAR Neutralizer Cathode Clogging}

Within $800 \mathrm{~h}$ of operation at the low-power $(0.5 \mathrm{~kW})$ run segment of the NSTAR ELT, the DC and $\mathrm{AC}$ characteristics of the neutralizer keeper performance began to increase and deposits formed within the cathode orifice. By the conclusion of the run segment, the neutralizer orifice was over 50 percent blocked and the neutralizer flow margin from plume-mode operation had decreased to zero (Ref. 39. Neutralizer failure due to orifice clogging resulting from extended operation at low-power was added to the known thruster failure modes as a result for the NSTAR thruster (Ref. 33). It was found that sufficient keeper current and/or flow rate can prevent clogging of the neutralizer by maintaining sufficient temperature to prevent temperature-dependent orifice-clogging mechanisms and increase flow margin from plume-mode operation, respectively. The neutralizer orifice and transition flow characteristics have been monitored closely during the NEXT LDT.

It was expected based upon the NSTAR ELT, that orifice clogging at a specific condition would be evident within $1,000 \mathrm{~h}$ of operation. However, no clogging of the neutralizer orifice has been witnessed for any NEXT LDT operating condition including a total of 9,700 consecutive hours at low beam current conditions. Images and measured data of the neutralizer orifice after each of the low-power run segments demonstrates the lack of clogging in the NEXT neutralizer orifice, shown in Figure 18 and Figure 19. The NEXT TT10 has demonstrated sufficient neutralizer keeper current and flow margin to prevent neutralizer orifice clogging and maintain sufficient flow margin from plume-mode even at low-power levels.

\section{NEXT LDT Test-to-Failure Prediction}

The first failure mode anticipated for the NEXT LDT is loss of structural integrity of the accelerator grid due to charge-exchange erosion. The measured data during the LDT validate the NEXT thruster groove penetration model. The operating condition with the worst groove erosion rate as a function of time is full-power operation ( $>37 \mathrm{kh}$ ) due to the high beam current density and high magnitude accelerator grid potential. The NEXT thruster service life model is used to predict the penetration of the grooves in the accelerator grid assuming test-to-failure of the NEXT LDT at full-power $(6.9 \mathrm{~kW}$ segment no. 2) and the results are shown in Figures 31 and 32. These graphs indicate groove penetration after $>45 \mathrm{kh}$ of operation and processing more than $800 \mathrm{~kg}$ of propellant throughput for the NEXT LDT 
throttling profile. This would result in a total impulse demonstrated of $30.7 \mathrm{MN} \cdot \mathrm{s}$, by far the highest total impulse ever demonstrated by any electric propulsion device. Evident in Figure 32 is that TL01 has the worst erosion rate as a function of propellant throughput due to the low total flow rate and high magnitude accelerator grid potential. However, the thruster is capable of operating more than $87 \mathrm{kh}$ at this condition and processing over $600 \mathrm{~kg}$ propellant with the TT10 inputs, well in excess of likely mission needs.

The agreement between post-test measurements of pit-and-groove patterns and maximum groove depth from the EM1 and PM1R short-duration wear tests at full-power have been compared to the measured NEXT LDT groove depth at full power for the TL40 operating segment (Refs. 19, 21, and 30). The data of Figure 32 show excellent agreement even though all three tests took place in difference vacuum facilities. In particular, the EM1 2,000 h wear test backsputter rate was half of that for the NEXT LDT at full-power. The fact that the groove depths are in agreement is evidence that the effect of backsputtered carbon on the accelerator erosion due to charge-exchange ion impingement is not significant over the range of backsputter rates for these two tests. The mean accelerator current at fullpower for the EM1 2,000 h wear test was $12.6 \mathrm{~mA}$ operating in VF6 at GRC with a backsputter rate of $1.5 \mu \mathrm{m} / \mathrm{kh}$. For comparison, the mean accelerator grid current for the NEXT LDT operating at full-power over the first 2,000 h of operation was $14.2 \mathrm{~mA}$ operating in VF16 at GRC with a backsputter rate of $3.0 \mu \mathrm{m} / \mathrm{kh}$. The 13 percent higher accelerator current for the NEXT LDT is a result of the lower pumping speed, while the higher background pressure results from the smaller facility size when comparing VF6 to VF16. These compete against each other in the charge-exchange erosion process. The increased accelerator current is an indicator that the local neutral pressure, hence charge-exchange ion production, is larger in VF16 thereby increasing the groove erosion rate. The increased backsputter rate slows the apparent groove erosion rate by providing carbon atoms to sputter erode instead of the grid material.

Several attempts were made to quantify the effect of testing in VF16 compared to in-space operating to determine whether the NEXT LDT thruster service life is representative of a thruster operated in space. Similar to comparing accelerator grid erosion between two facilities (VF6 and VF16) the comparison will be made between VF16 and space where the space environment is assumed to have infinite pumping speed and zero backsputter rate. Comparisons between VF16 and in-space operation require the quantification of the competing effects of elevated background pressure and backsputter rate for fullpower operation. Application of a model developed to predict the effect of backsputtering on grid erosion, with a $3 \mu \mathrm{m} / \mathrm{kh}$ back-sputter rate and center-radius aperture ion impingement current density, estimates a maximum of 10 percent reduction in erosion near the beam center, where pit and groove erosion rate is highest, during the NEXT LDT due to back-sputtered carbon (Ref. 60). Additional analyses have been performed to predict the impact of the backsputtered carbon deposition on the accelerator grid utilizing the MICHELLE PIC-code (Ref. 61). The resulting analysis estimates a 10 to 30 percent reduction in the maximum groove erosion due to carbon deposition in the LDT (Ref. 61). From NSTAR data on DS1, the impingement accelerator current in space was $\sim 25$ percent less than the NSTAR data obtained during preflight measurements at $1.50 \mathrm{~A}$ beam current and $25.56 \mathrm{sccm}$ total flow rate in a test facility operating with a background pressure level of $3.5 \times 10^{-6}$ Torr (Refs. 33, 41, and 45). The NEXT LDT is operating at slightly higher operating background pressures at full-power, resulting in measured NEXT accelerator currents that would be $\geq 25$ percent larger than those in space and therefore accelerator grid erosion would be approximately 25 percent less in space. The combined effects of elevated background pressure in the test facility and backsputtered carbon deposition approximately cancel out, and therefore the LDT groove wear is expected to be representative of thruster operation in space.

There is an ongoing internal research and development program to manufacture pyrolitic graphite ion optics for the NEXT thruster at GRC. Two sets of grids have been manufactured and one set is ready for performance testing. This switch in grid materials would further increase the NEXT thruster service life by drastically decreasing the charge-exchange erosion of the accelerator grid through the use of lower sputter yield carbon. A conservative estimate of the reduction in sputter yields a value of at least $1 / 10^{\text {th }}$ comparing molybdenum and carbon (Ref. 57). Thus, switching to pyrolitic graphite would provide an order of magnitude increase in the thruster service life. This would likely shift the failure of the thruster to another thruster wear-out mode (Ref. 18). 


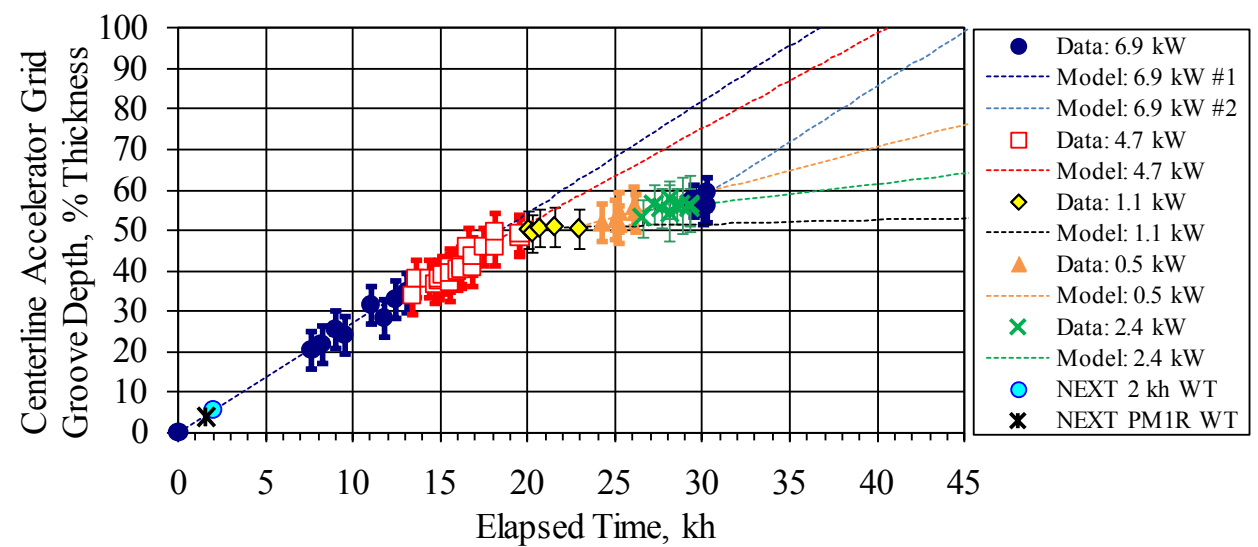

Figure 31.-NEXT centerline accelerator grid groove penetration depth as a function of operating duration. Extrapolation to groove penetration assuming $6.9 \mathrm{~kW}$ estimates failure after $45 \mathrm{kh}$.

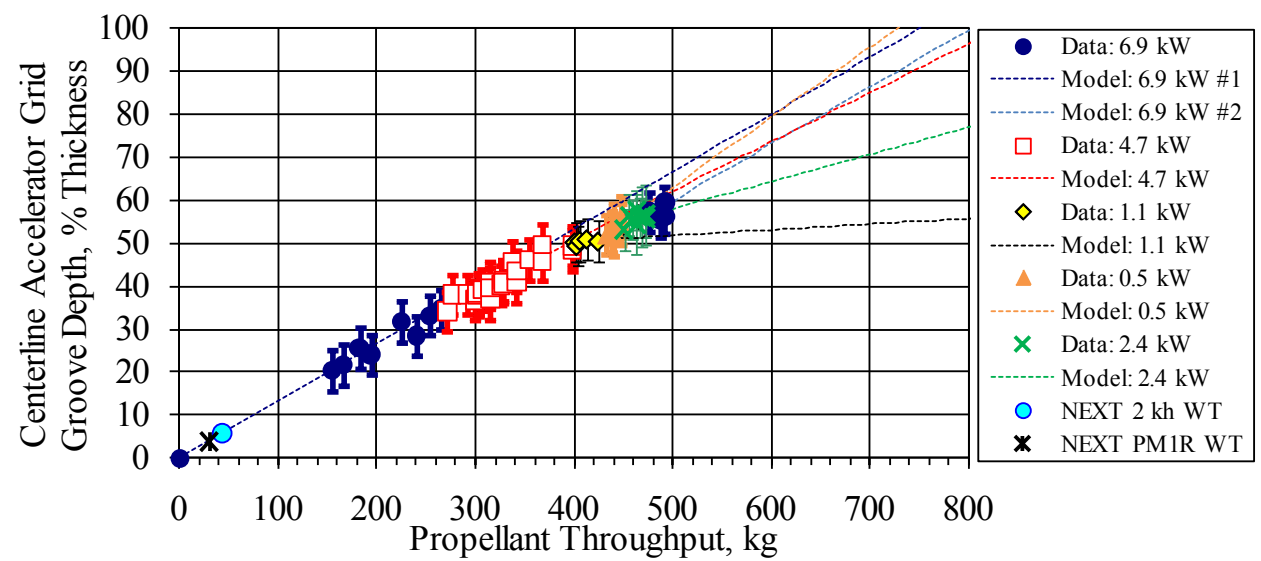

Figure 32.-NEXT centerline accelerator grid groove penetration depth as a function of propellant processed. Extrapolation to groove penetration assuming $6.9 \mathrm{~kW}$ estimates failure after $800 \mathrm{~kg}$.

Predictions for accelerator grid aperture geometries, cathode orifice geometries, and electron backstreaming margin are output by the NEXT service life assessment for a given throttling profile. For the case of the NEXT LDT, where the accelerator apertures across the grid face have eroded to their worst-case final geometries, no additional changes in aperture geometries are expected. This prediction, combined with the lack of a change in ion optics' grid-gap, leads to negligible change in the electron backstreaming margin for the remaining duration of the NEXT LDT. Thus, the NSTAR first failure mode of electron backstreaming will not be an issue with NEXT thrusters. Predictions for other cathode wearout modes such as barium depletion and keeper erosion are shown in Figure 33 indicating at most 50 percent barium depletion for either cathode by the time accelerator grid groove penetration is predicted (Refs. 17 and 18). 


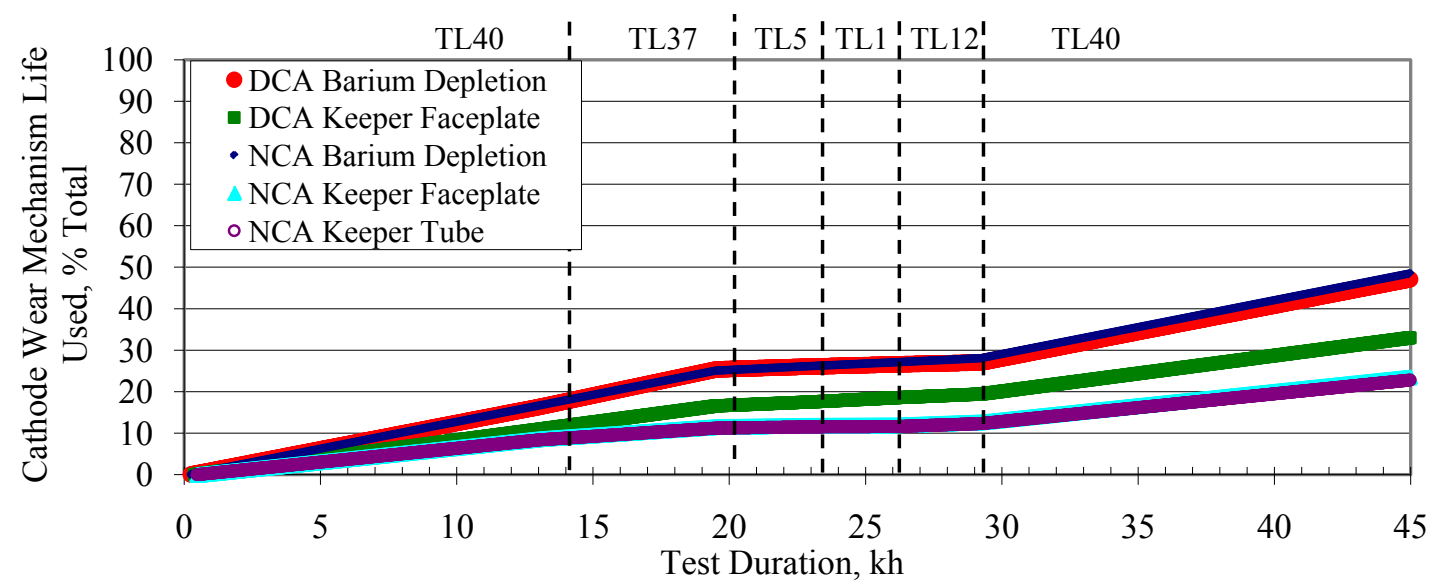

Figure 33.-NEXT LDT cathode wear-out mode progressions based upon NEXT service life assessment.

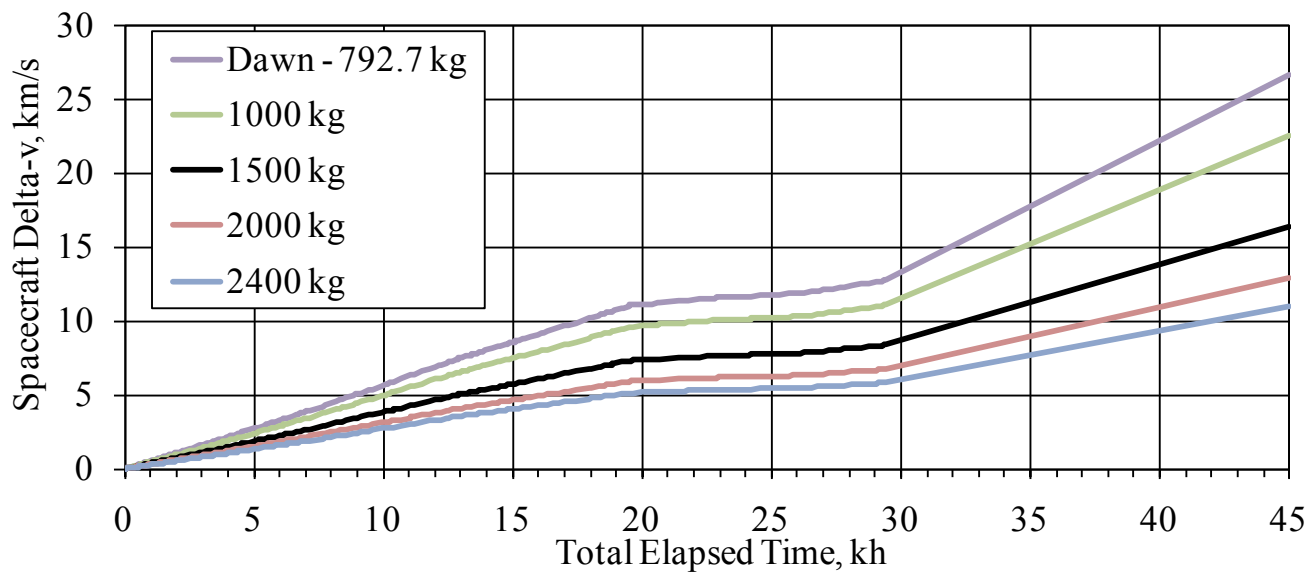

Figure 34.-Delta-v estimates for various spacecraft dry masses (800 kg xenon added to the indicated dry mass for the initial mass) operated in the NEXT LDT profile to thruster failure.

With a higher-power, higher-thrust, and significantly higher propellant throughput capability thruster, the NEXT thruster can provide significant mission benefits compared to the previous state-of-the-art NSTAR thruster. For example, the case of the Dawn spacecraft, which utilizes three NSTAR thrusters will be considered. The Dawn spacecraft dry mass $(747.1 \mathrm{~kg})$ plus hydrazine $(45.6 \mathrm{~kg})$ has an initial mass of $792.7 \mathrm{~kg}$ (without xenon). This initial mass plus an additional $800 \mathrm{~kg}$ of xenon propellant could be operated in the same profile as the NEXT LDT, providing roughly $26 \mathrm{~km} / \mathrm{s}$ delta-v to the spacecraft by the single NEXT thruster. The delta-v as a function of time for the Dawn spacecraft mass and other spacecraft dry masses operated in the NEXT LDT profile are shown in Figure 34. This is not meant as a direct comparison, but only a rough estimate that does not take into account the mass savings by eliminating NSTAR thruster strings (1+1 NEXT versus $2+1$ NSTAR), any details or restraints about the trajectory required to perform the Dawn mission, or the mass penalty of the solar arrays to process the additional power required for full-power NEXT thruster operation. For comparison, the total delta-v provided by the three-string (one cold spare) NSTAR IPS on Dawn is expected to reach $11 \mathrm{~km} / \mathrm{s}$ over a $10 \mathrm{yr}$ time period (Ref. 62). The spacecraft total delta-v operated in a NEXT LDT throttling profile to the predicted thruster failure as a function of spacecraft dry mass is shown in Figure 35. The NEXT LDT profile can impart a delta-v equivalent to that required for the Dawn mission on a spacecraft dry mass of $2400 \mathrm{~kg}$ - $3 X$ Dawn (wet mass of $3200 \mathrm{~kg}$ ). 


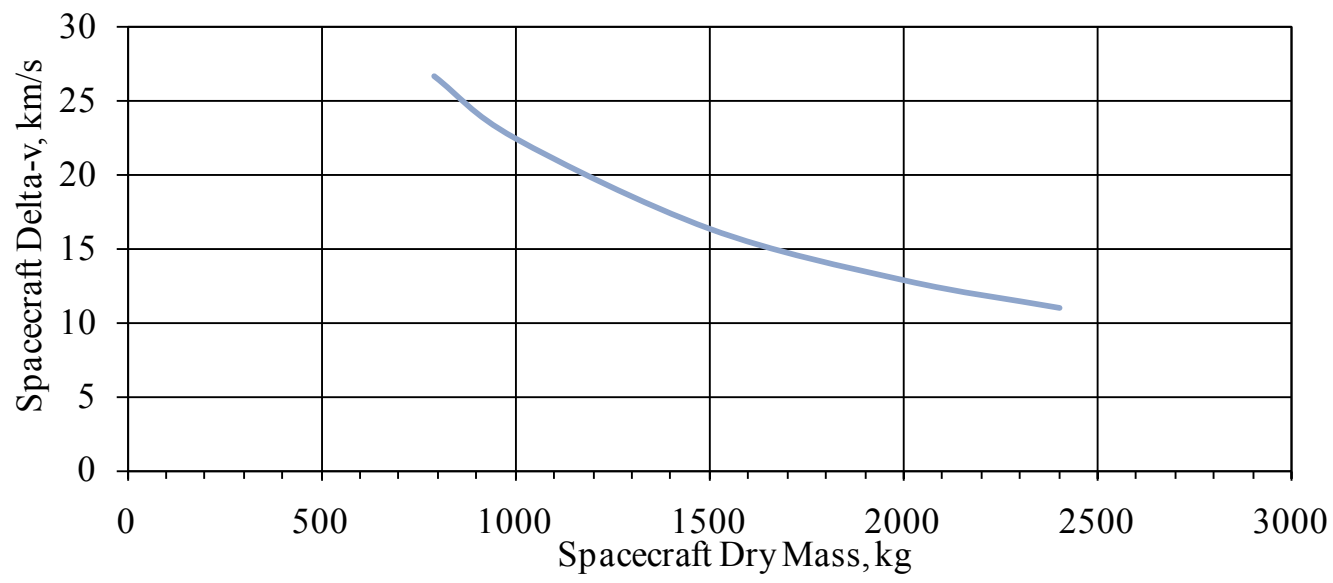

Figure 35.-Total Delta-v estimates for various spacecraft dry masses (800 kg xenon added to indicated dry mass for the initial mass) operated in the NEXT LDT profile to thruster failure.

\section{Conclusion}

The NEXT LDT is the major component of the testing part of the comprehensive thruster service life assessment that combines multiple wear tests and modeling. The thruster has recently surpassed the total operating duration for any electric propulsion thruster - passing the $30,352 \mathrm{~h}$ record previously held by the NSTAR ELT, while maintaining a high level of performance. The NEXT LDT also holds the record for the highest propellant throughput demonstrated $(495 \mathrm{~kg})$ for any ion or Hall thruster, the highest total impulse demonstrated by any high-TRL electric propulsion thruster $(18.2 \mathrm{MN} \cdot \mathrm{s})$, and the longest duration test of a hollow cathode. The thruster surpassed the project qualification propellant throughput $(450 \mathrm{~kg})$ in CY09. The NEXT LDT has validated the thruster service models across the broad throttle range of the NEXT thruster. The test has demonstrated that multiple NSTAR failure modes, including the NSTAR first failure mode, have been mitigated by the NEXT design. The LDT has been operated in a missionlike profile throttling power down with testing duration. The go-forward plan is to operate the thruster at full-power until failure. The NEXT LDT test article is predicted to reach its first failure mode, predicted to be loss of structural integrity of the accelerator grid due to charge-exchange ion impingement, after $>45 \mathrm{kh}$ and processing greater than $800 \mathrm{~kg}$. By the end of the LDT, the total impulse demonstrated should exceed $30.7 \mathrm{MN} \cdot \mathrm{s}$ - the highest total impulse demonstrated of any electric propulsion thruster. For a representative spacecraft dry mass $(792.7 \mathrm{~kg}$ with hydrazine for the Dawn mission) a single NEXT thruster operated in the NEXT LDT profile to the predicted thruster failure $(800 \mathrm{~kg})$ would impart a significant delta-v $(26 \mathrm{~km} / \mathrm{s})$ to the spacecraft or could substantially increase the delivered payload mass by a factor of three compared to the anticipated delta-v $(11 \mathrm{~km} / \mathrm{s})$ and known payload mass for the Dawn mission utilizing previous state-of-the-art NSTAR thrusters. 


\section{Appendix}

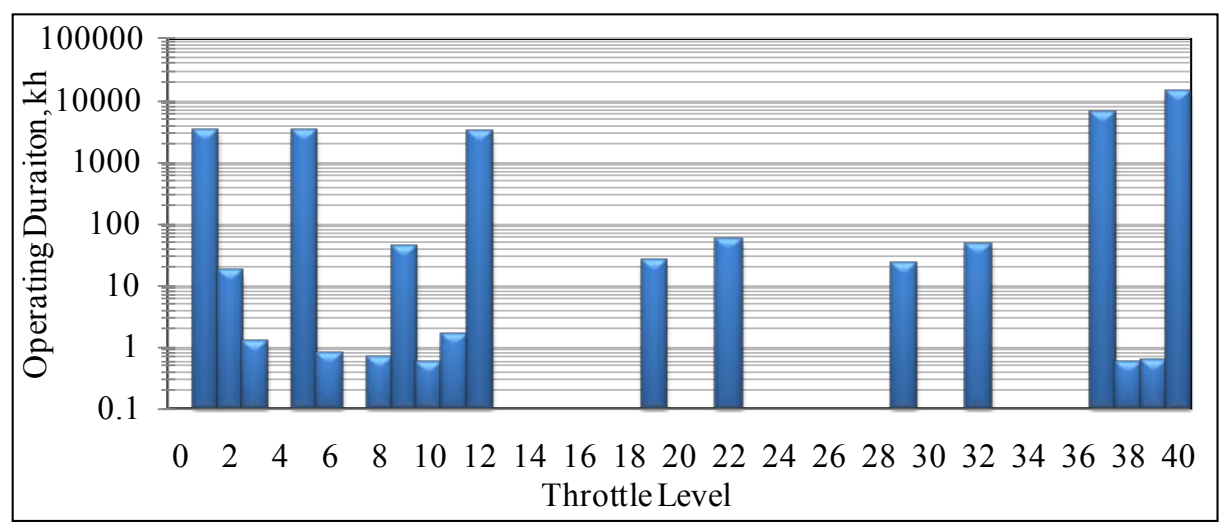

Figure 36.-NEXT LDT semi-log chart of operating duration as a function of throttle level.

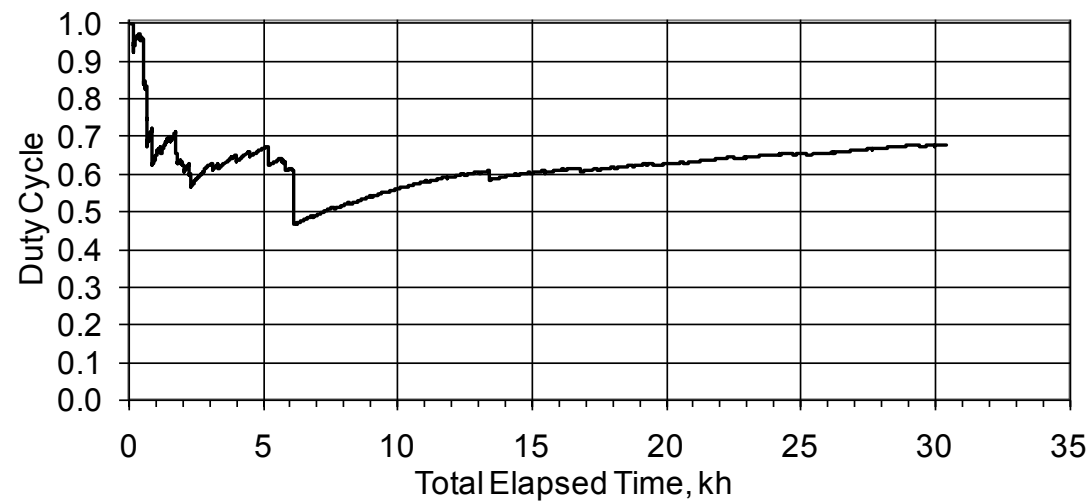

Figure 37.-NEXT LDT testing duty cycle as a function of test duration.

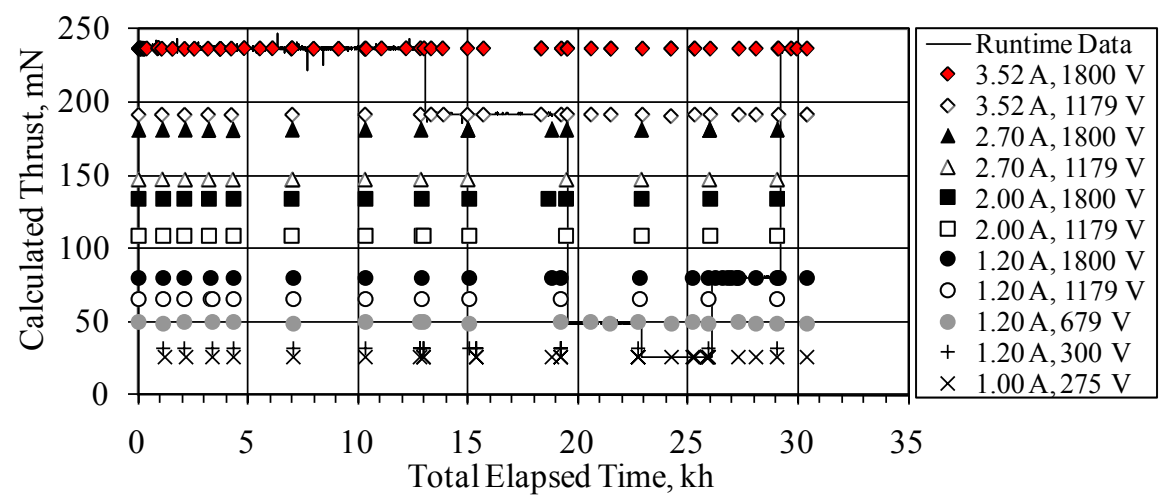

Figure 38.-NEXT LDT calculated thrust across the throttle table as a function of test duration. 


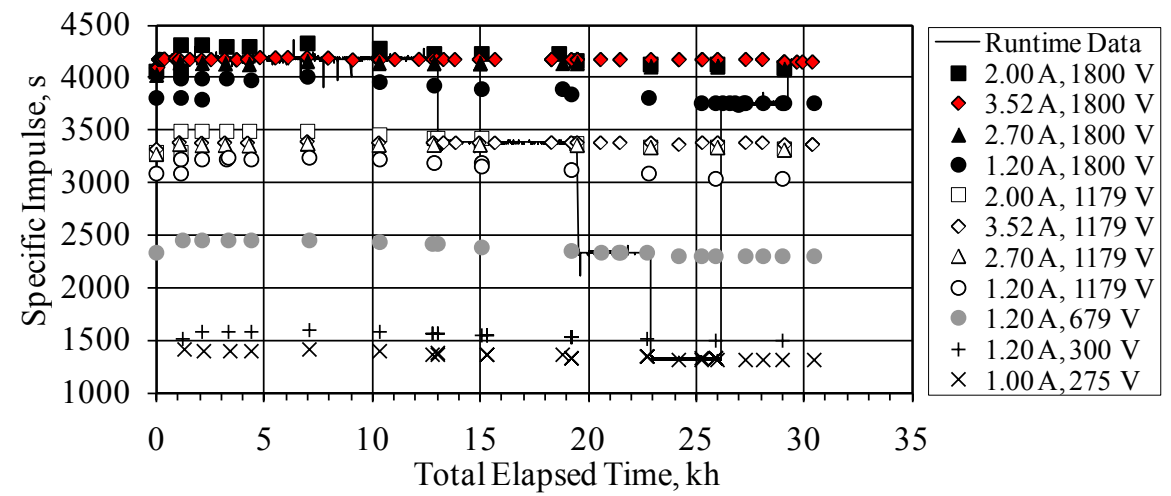

Figure 39.-NEXT LDT specific impulse across the throttle table as a function of test duration.

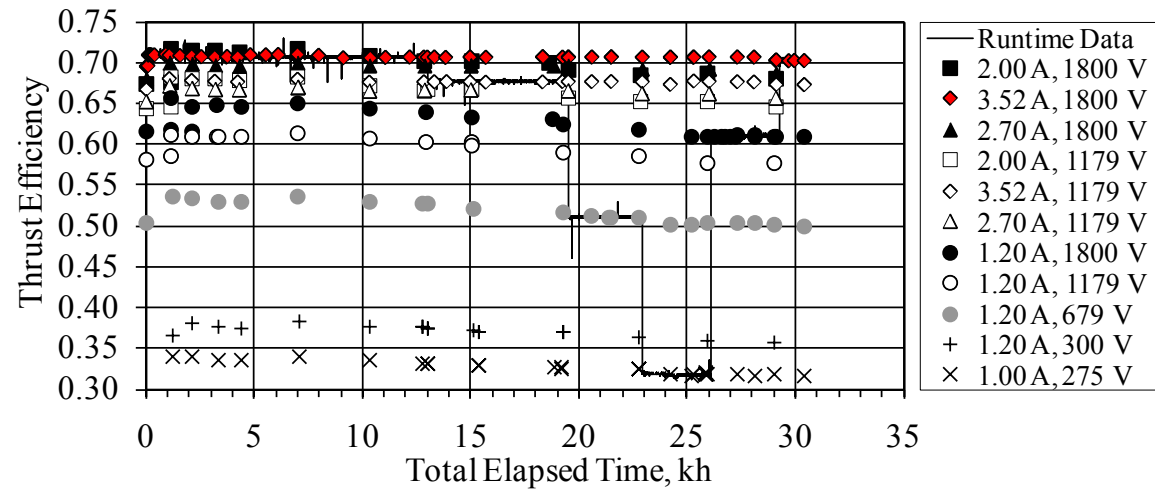

Figure 40.-NEXT LDT thrust efficiency across the throttle table as a function of test duration.

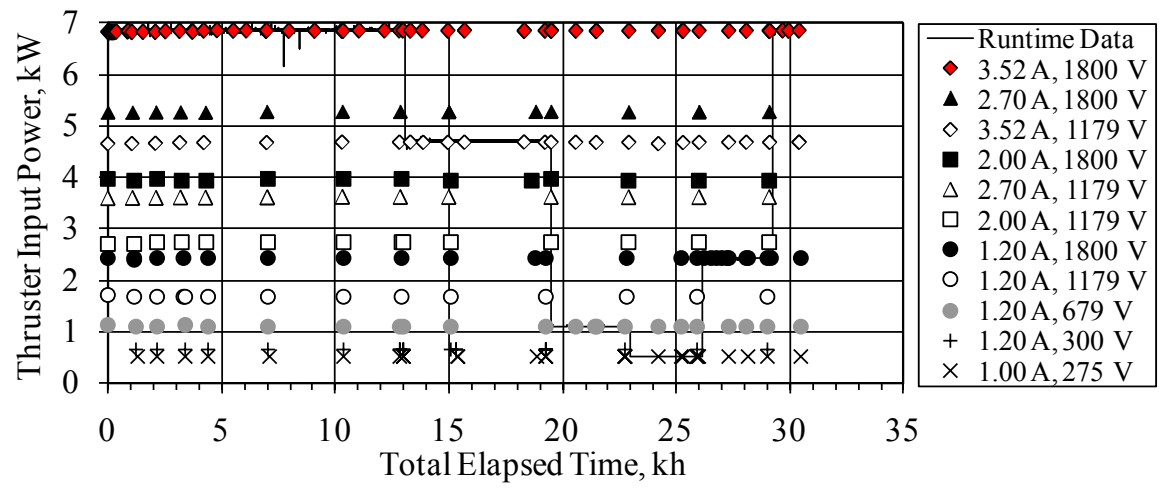

Figure 41.-NEXT LDT input power across the throttle table as a function of test duration. 


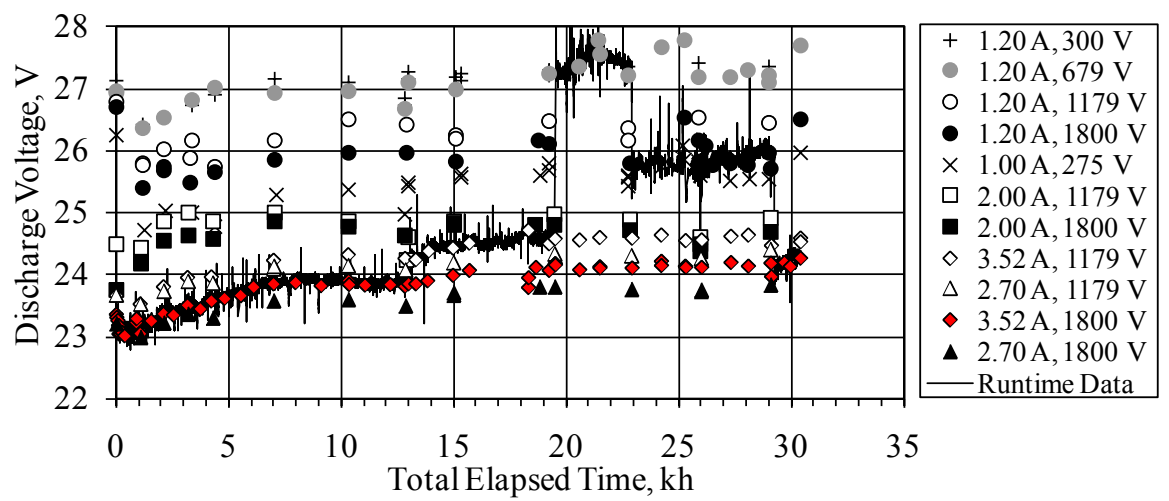

Figure 42.-NEXT LDT discharge voltage across the throttle table as a function of test duration.

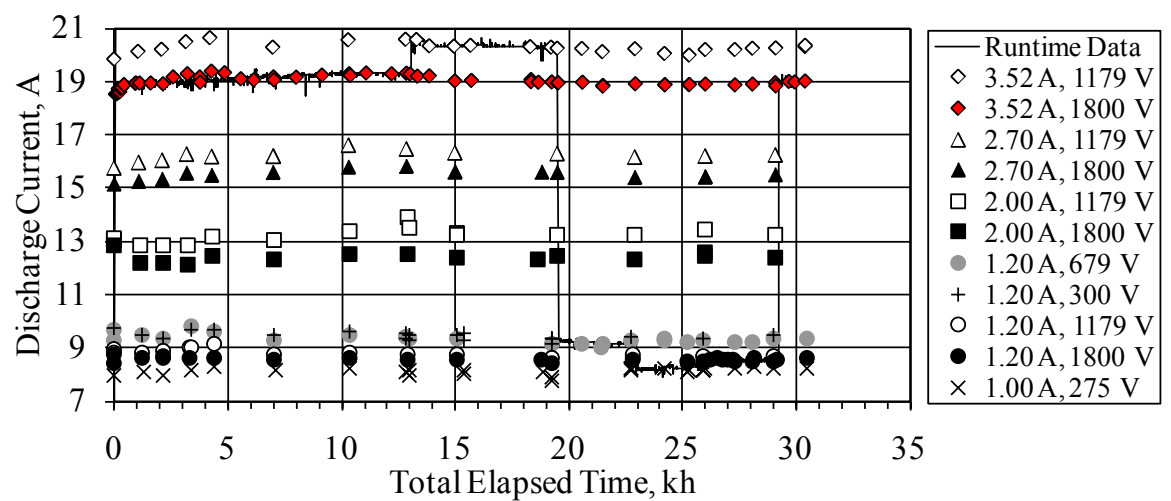

Figure 43.-NEXT LDT discharge current across the throttle table as a function of test duration.

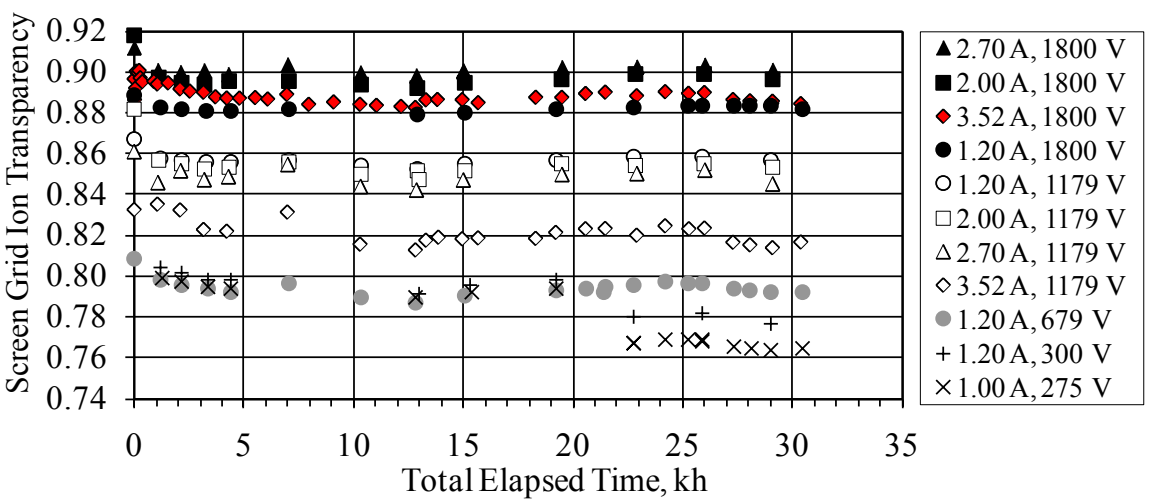

Figure 44.-NEXT LDT screen grid ion transparency as a function of test duration. 


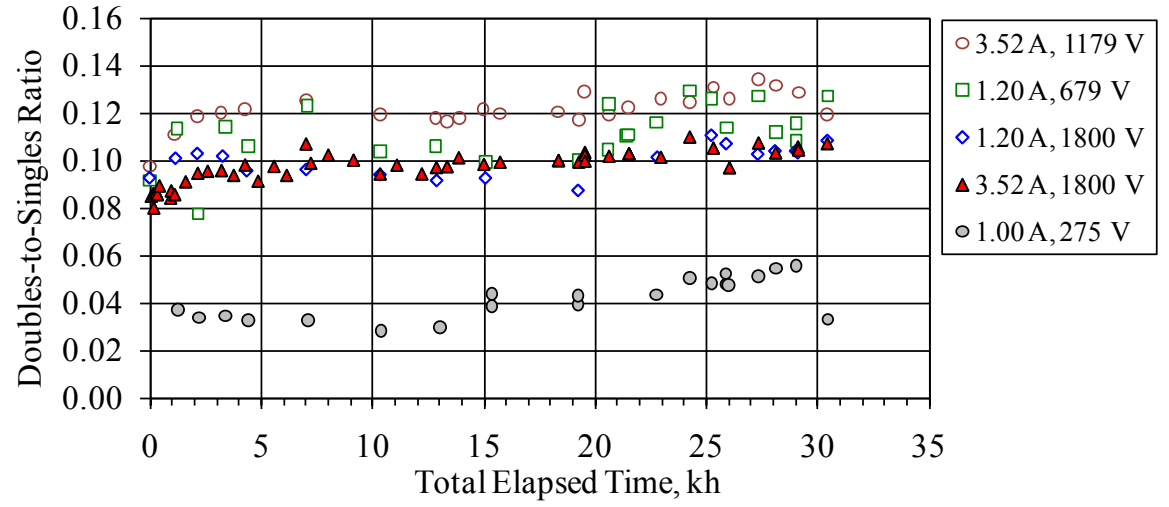

Figure 45.-Farfield centerline NEXT LDT doubles-to-singles current ratio signature at the run segment conditions versus test duration.

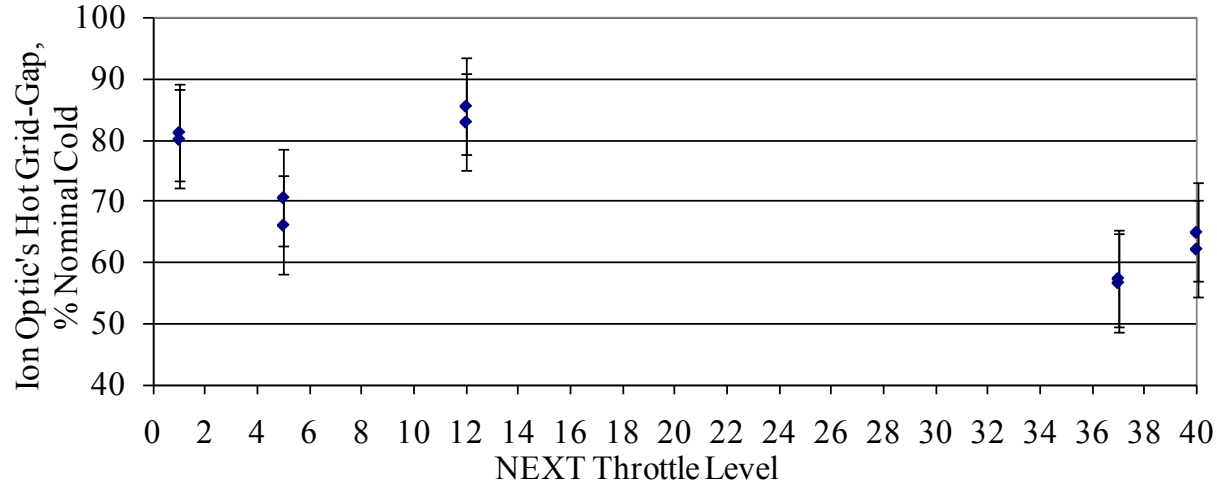

Figure 46.-NEXT LDT PM ion optics' hot grid-gap for extended run segment throttle levels. 


\section{References}

1. Patterson, M.J. and Benson, S.W., "NEXT Ion Propulsion System Development Status and Performance," AIAA-2007-5199, 43 ${ }^{\text {rd }}$ AIAA/ASME/SAE/ASEE Joint Propulsion Conference and Exhibit, Cincinnati, OH, Jul. 8-11, 2007.

2. Polk, J.E., et al., "Demonstration of the NSTAR Ion Propulsion System on the Deep Space One Mission," IEPC-2001-075, $27^{\text {th }}$ International Electric Propulsion Conference, Pasadena, CA, Oct. 15-19, 2001.

3. Rayman, M.D., "The Successful Conclusion of the Deep Space 1 Mission: Important Results Without a Flashy Title," Space Technology, Vol. 23, pp. 185-196, 2003.

4. Brophy, J.R., et al., "Development and Testing of the Dawn Ion Propulsion System," AIAA-20064319, $42^{\text {nd }}$ AIAA/ASME/SAE/ASEE Joint Propulsion Conference and Exhibit, Sacramento, CA, Jul. 9-12, 2006.

5. Benson, S. W. and Patterson, M. J., "NASA's Evolutionary Xenon Thruster (NEXT) Ion Propulsion Technology Development Status in 2009," IEPC-2009-150, $31^{\text {st }}$ International Electric Propulsion Conference, Ann Arbor, MI, Sep. 20-24, 2009.

6. Patterson, M.J., et al., "NEXT Multi-Thruster Array Test - Engineering Demonstration," AIAA2006-5180, $42^{\text {nd }}$ AIAA/ASME/SAE/ASEE Joint Propulsion Conference and Exhibit, Sacramento, CA, Jul. 9-12, 2006.

7. Soulas, G.C., et al., "NEXT Single String Integration Test Results," AIAA-2009-4816, 45 ${ }^{\text {th }}$ AIAA/ ASME/SAE/ASEE Joint Propulsion Conference and Exhibit, Denver, CO, Aug. 2-5, 2009.

8. Hoskins, W.A., et al., "NEXT Ion Propulsion System Production Readiness," AIAA-2007-5856, 43 ${ }^{\text {rd }}$ AIAA/ASME/SAE/ASEE Joint Propulsion Conference and Exhibit, Cincinnati, OH, Jul. 8-11, 2007.

9. Snyder, J.S., Anderson, J.R., Van Noord, J.L., and Soulas, G.C., "Environmental Testing of the NEXT PM1 Ion Engine," AIAA-2007-5275, 43 ${ }^{\text {rd }}$ AIAA/ASME/SAE/ASEE Joint Propulsion Conference and Exhibit, Cincinnati, OH, Jul. 8-11, 2007.

10. Crofton, M.W., et al., "Characterization of the NASA NEXT Thruster," AIAA-2009-4815, 45 AIAA/ASME/SAE/ASEE Joint Propulsion Conference and Exhibit, Denver, CO, Aug. 2-5, 2009.

11. Herman, D.A., Pinero, L.R., and Sovey, J.S., "NASA's Evolutionary Xenon Thruster (NEXT) Component Verification Testing," AIAA-2008-4812, 44 ${ }^{\text {th }}$ AIAA/ASME/SAE/ASEE Joint Propulsion Conference and Exhibit, Hartford, CT, Jul. 21-23, 2008.

12. Pinero, L.R., Hopson, M., Todd, P.C., and Wong, B., "Performance of the NEXT Engineering Model Power Processing Unit," AIAA-2007-5214, 43 ${ }^{\text {rd }}$ AIAA/ASME/SAE/ASEE Joint Propulsion Conference and Exhibit, Cincinnati, OH, Jul. 8-11, 2007.

13. Herman, D.A., Soulas, G.C., and Patterson, M.J., "Performance Evaluation of the Prototype-Model NEXT Ion Thruster," AIAA-2007-5212 and NASA/TM-2008-215029, 43 ${ }^{\text {rd }}$ AIAA/ASME/SAE/ ASEE Joint Propulsion Conference and Exhibit, Cincinnati, OH, Jul. 8-11, 2007.

14. Snyder, J.S., et al., "Vibration Test of a Breadboard Gimbal for the NEXT Ion Engine," AIAA-2006$4665,42^{\text {nd }}$ AIAA/ASME/SAE/ASEE Joint Propulsion Conference and Exhibit, Sacramento, CA, Jul. 9-12, 2006.

15. Aadland, R.S., Frederick, H., Benson, S.W., and Malone, S.P., "Development Results of the NEXT Propellant Management System," JANNAF 2005-0356DW, JANNAF $2^{\text {nd }}$ Liquid Propulsion Subcommittee and $1^{\text {st }}$ Spacecraft Propulsion Subcommittee Joint Meeting, Monterey, CA, Dec. 5-8, 2005.

16. Dankanich, J.W., Brophy, J.R., and Polk, J.E., "Lifetime Qualification Standard for Electric Thrusters," AIAA-2009-5095, 45 ${ }^{\text {th }}$ AIAA/ASME/SAE/ASEE Joint Propulsion Conference and Exhibit, Denver, CO, Aug. 2-5, 2009.

17. Van Noord, J.L., "Lifetime Assessment of the NEXT Ion Thruster," AIAA-2007-5274, 43 ${ }^{\text {rd }}$ AIAA/ASME/SAE/ASEE Joint Propulsion Conference and Exhibit, Cincinnati, OH, July 8-11, 2007. 
18. Van Noord, J.L. and Herman, D.A., "Application of the NEXT Ion Thruster Lifetime Assessment to Thruster Throttling," AIAA-2008-4526, 44 ${ }^{\text {th }}$ AIAA/ASME/SAE/ASEE Joint Propulsion Conference and Exhibit, Hartford, CT, Jul. 21-23, 2008.

19. Soulas, G.C., et al., "NEXT Ion Engine 2000 Hour Wear Test Results," AIAA-2004-3791, 40 ${ }^{\text {th }}$ AIAA/ASME/SAE/ASEE Joint Propulsion Conference and Exhibit, Fort Lauderdale, FL, July 11-14, 2004

20. Soulas, G.C. and Patterson, M.J., "NEXT Ion Thruster Performance Dispersion Analyses," AIAA2007-5213, 43 ${ }^{\text {rd }}$ AIAA/ASME/SAE/ASEE Joint Propulsion Conference and Exhibit, Cincinnati, OH, Jul. 8-11, 2007.

21. Van Noord, J. L., Soulas, G. C., and Sovey, J. S., "NEXT PM1R Ion Thruster and Propellant Management System Wear Test Results," IEPC-2009-163, $31^{\text {st }}$ International Electric Propulsion Conference, Ann Arbor, MI, Sep. 20-24, 2009.

22. Hoskins, W.A., et al., "Development of a Prototype Model Ion Thruster for the NEXT System," AIAA-2004-4111, 40 ${ }^{\text {th }}$ AIAA/ASME/SAE/ASEE Joint Propulsion Conference and Exhibit, Fort Lauderdale, FL, Jul. 11-14, 2004.

23. Soulas, G.C., Domonkos, M.T., and Patterson, M.J., "Performance Evaluation of the NEXT Ion Engine," AIAA-2003-5278, 39 ${ }^{\text {th }}$ AIAA/ASME/SAE/ASEE Joint Propulsion Conference and Exhibit, Huntsville, AL, Jul. 20-23, 2003.

24. Patterson, M.J., et al., "NEXT: NASA's Evolutionary Xenon Thruster," AIAA-2002-3832, 38 AIAA/ASME/SAE/ASEE Joint Propulsion Conference and Exhibit, Indianapolis, IN, July 7-10, 2002.

25. Frandina, M.M., et al., "Status of the NEXT Ion Thruster Long Duration Test," AIAA-2005-4065, $41^{\text {st }}$ AIAA/ASME/SAE/ASEE Joint Propulsion Conference and Exhibit, Tucson, AZ, Jul. 10-13, 2005.

26. Herman, D. A., Soulas, G. C., and Patterson, M. J., "Performance Characteristics of the NEXT LongDuration Test after 16,550 h and $337 \mathrm{~kg}$ of Xenon Processed," AIAA-2008-4527, 44 ${ }^{\text {th }}$

AIAA/ASME/SAE/ASEE Joint Propulsion Conference and Exhibit, Hartford, CT, Jul. 21-23, 2008.

27. Herman, D.A., Soulas, G.C., and Patterson, M.J., "NEXT Long-Duration Test Plume and Wear Characteristics after 16,550 h of Operation and $337 \mathrm{~kg}$ of Xenon Processed," AIAA-2008-4919, 44 ${ }^{\text {th }}$ AIAA/ASME/SAE/ASEE Joint Propulsion Conference and Exhibit, Hartford, CT, Jul. 21-23, 2008.

28. Herman, D.A., Soulas, G.C., and Patterson, M.J., "Status of the NEXT Long-Duration Test after 23,300 Hours of Operation," AIAA-2009-4917, $45^{\text {th }}$ AIAA/ASME/SAE/ASEE Joint Propulsion Conference and Exhibit, Denver, CO, Aug. 2-5, 2009.

29. Herman, D.A., Soulas, G.C., and Patterson, M.J., "NEXT Long-Duration Test Neutralizer Performance and Erosion Characteristics," IEPC-2009-154, $31^{\text {st }}$ International Electric Propulsion Conference, Ann Arbor, MI, Sep. 20-24, 2009.

30. Kamhawi, H., Soulas, G.C., and Patterson, M., "NEXT Ion Engine 2000 hour Wear Test Plume and Erosion Results," AIAA-2004-3792, 40 ${ }^{\text {th }}$ AIAA/ASME/SAE/ASEE Joint Propulsion Conference and Exhibit, Fort Lauderdale, FL, Jul. 11-14, 2004.

31. Brophy, J.R., et al., "The Ion Propulsion System for Dawn," AIAA-2003-4542, $39^{\text {th }}$ AIAA/ASME/ SAE/ASEE Joint Propulsion Conference and Exhibit, Huntsville, AL, July 20-23, 2003.

32. Brophy, J.R., et al., "Status of the Dawn Ion Propulsion System," AIAA-2004-3433, 40 ${ }^{\text {th }}$ AIAA/ ASME/SAE/ASEE Joint Propulsion Conference and Exhibit, Fort Lauderdale, FL, July 11-14, 2004.

33. Sengupta, A., et al., "The 30,000-Hour Extended-Life Test of the Deep Space 1 Flight Spare Ion Thruster," NASA/TP-2004-213391, The NASA Jet Propulsion Laboratory and Glenn Research Center, Pasadena, CA, Mar. 2005.

34. Myers, R.M., "Proceedings of the Nuclear Electric Propulsion Workshop, Volume 1: Introductory Material and Thruster Concepts, Section: "MPD Thruster Technology"," JPL D-9512 Vol. 1, Jun. 19-22, 1990.

35. Soulas, G.C., "Design and Performance of $40 \mathrm{~cm}$ Ion optics," IEPC-01-090, $27^{\text {th }}$ International Electric Propulsion Conference, Pasadena, CA, October 15-19, 2001. 
36. Patterson, M.J., Haag, T.W., and Hovan, S.A., "Performance of the NASA $30 \mathrm{~cm}$ Ion thruster," IEPC Paper 93-108, $23^{\text {rd }}$ International Electric Propulsion Conference, Seattle, WA, Sep. 13-16, 1993.

37. Herman, D.A., "NASA's Evolutionary Xenon Thruster (NEXT) Project Qualification Propellant Throughput Milestone: Performance, Erosion, and Thruster Service Life Prediction after $450 \mathrm{~kg}$," CPIAC JSC 2010-0015EH, JANNAF $7^{\text {th }}$ Modeling and Simulation, $5^{\text {th }}$ Liquid Propulsion, and $4^{\text {th }}$ Spacecraft Propulsion Joint Subcommittee Meeting, Colorado Springs, CO, May 3-7, 2010.

38. Stueber, T. and Soulas, G. C., "Electrostatic Ion Thruster Diagnostic Uncertainty Analysis," NASA/ TP-2007-214665, Jul. 2007.

39. Sengupta, A., et al., "An Overview of the Results from the 30,000 Hr Life Test of Deep Space 1 Flight Spare Engine," AIAA-2004-3608, 40 ${ }^{\text {th }}$ AIAA/ASME/SAE/ASEE Joint Propulsion Conference and Exhibit, Fort Lauderdale, FL, Jul. 11-14, 2004.

40. Goebel, D.M., Polk, J.E., and Mikellides, I., "Ion Thruster Performance Impacts due to Cathode Wear," AIAA-2009-4920, 45 ${ }^{\text {th }}$ AIAA/ASME/SAE/ASEE Joint Propulsion Conference and Exhibit, Denver, CO, Aug. 2-5, 2009.

41. Anderson, J.R., et al., "Results of an On-going Long Duration Ground Test of the DS1 Flight Spare Ion Engine," AIAA-1999-2857, 35 ${ }^{\text {th }}$ AIAA/ASME/SAE/ASEE Joint Propulsion Conference and Exhibit, Los Angeles, CA, Jun. 20-24, 1999.

42. Polk, J. E., et al., "An Overview of the Results from an 8200 Hour Wear Test of the NSTAR Ion Thruster," AIAA-1999-2446, 35 ${ }^{\text {th }}$ AIAA/ASME/SAE/ASEE Joint Propulsion Conference and Exhibit, Los Angeles, CA, June 20-24, 1999.

43. Polk, J.E., et al., "A 1000 Hour Wear Test of the NASA NSTAR Ion Thruster," AIAA-1996-2784, $32^{\text {nd }}$ AIAA/ASME/SAE/ASEE Joint Propulsion Conference and Exhibit, Lake Buena Vista, FL, Jul. $1-3,1996$.

44. Anderson, J.R., et al., "Performance Characteristics of the NSTAR Ion Thruster During an On-Going Long Duration Ground Test," 2000 IEEE Aerospace Conference Proceedings, Vol. 4, pp. 123-148, Mar. 2000.

45. Polk, J.E., et al., "Performance of the NSTAR Ion Propulsion System on the Deep Space One Mission," AIAA-2001-0965, 39 ${ }^{\text {th }}$ AIAA Aerospace Sciences Meeting and Exhibit Joint Propulsion Conference, Reno, NV, Jan. 8-11, 2001.

46. Soulas, G.C., Foster, J.E., and Patterson, M.J., "Performance of Titanium Optics on a NASA $30 \mathrm{~cm}$ Ion Thruster," AIAA-2000-3814, 36 ${ }^{\text {th }}$ AIAA/ASME/SAE/ASEE Joint Propulsion Conference and Exhibit, Huntsville, AL, Jul. 16-19, 2000.

47. Mikellides, I., et al., "Neutralizer Hollow Cathode Simulations and Comparisons with Ground Test Data," IEPC-2009-20, $31^{\text {st }}$ International Electric Propulsion Conference, Ann Arbor, MI, Sep. 20 24, 2009.

48. Herman, D.A., Soulas, G.C., and Patterson, M.J., "Status of the NEXT Ion Thruster Long-Duration Test after 10,100 $\mathrm{h}$ and $207 \mathrm{~kg}$ Demonstrated," AIAA-2007-5272 and NASA/TM-2008-215030, $43^{\text {rd }}$ AIAA/ASME/SAE/ASEE Joint Propulsion Conference and Exhibit, Cincinnati, OH, Jul. 8-11, 2007.

49. Williams, G.J., "High-Power Electric Propulsion (HiPEP) 2,000-Hour Post-Test Report," NEXT Internal Report, NASA Glenn Research Center, Cleveland, OH, Sep. 2006.

50. Britton, M., Soulas, G.C., Kamhawi, H., and Snyder, A., "Destructive Analysis of the NEXT 2000Hour Wear Test Hollow Cathode Assemblies," NASA/TM-2005-213387, NASA Glenn Research Center, Cleveland, OH, Jul. 2005.

51. Williams, G.J., et al., "Results of the $2000 \mathrm{hr}$ Wear Test of the HiPEP Ion Thruster with Pyrolitic Graphite Ion Optics," AIAA-2006-4668, 42 ${ }^{\text {nd }}$ AIAA/ASME/SAE/ASEE Joint Propulsion Conference and Exhibit, Sacramento, CA, Jul. 9-12, 2006.

52. Kuharski, R.A., et al., "Ion Engine Neutralizer Erosion in Lab and Space," AIAA-2006-3880, 41 ${ }^{\text {st }}$ AIAA/ASME/SAE/ASEE Joint Propulsion Conference and Exhibit, Tucson, AZ, Jul. 10-13, 2005. 
53. Malone, S.P., "Investigation of NEXT Ion Optics Erosion Processes using Computational Modeling," JANNAF 2005-0356DV, JANNAF $2^{\text {nd }}$ Liquid Propulsion Subcommittee and $1^{\text {st }}$ Spacecraft Propulsion Subcommittee Joint Meeting, Monterey, CA, Dec. 5-8, 2005.

54. Sengupta, A., et al., "Performance Characteristics of the Deep Space 1 Flight Spare Ion Thruster Long Duration Test after 21,300 Hours of Operation," AIAA-2002-3959, 38 ${ }^{\text {th }}$ AIAA/ASME/SAE/ ASEE Joint Propulsion Conference and Exhibit, Indianapolis, IN, Jul. 7-10, 2002.

55. Sengupta, A., Brophy, J.R., and Goodfellow, K.D., "Status of the Extended Life Test of the Deep Space 1 Flight Spare Ion Engine after 30,352 Hours of Operation," AIAA-2003-4558, 39 ${ }^{\text {th }}$ AIAA/ASME/SAE/ASEE Joint Propulsion Conference and Exhibit, Huntsville, AL, Jul. 20-23, 2003.

56. Kamhawi, H., Soulas, G.C., and Patterson, M., "NEXT Ion Engine 2000 hour Wear Test Plume and Erosion Results," AIAA-2004-3792, 40 ${ }^{\text {th }}$ AIAA/ASME/SAE/ASEE Joint Propulsion Conference and Exhibit, Fort Lauderdale, FL, Jul. 11-14, 2004.

57. Doerner, R.P., Whyte, D.G., and Goebel, D.M., "Sputtering Yield Measurements during Low Energy Xenon Plasma Bombardment," Journal of Applied Physics, Vol. 93, No. 9, pp. 5816-5823, May 1, 2003.

58. Doerner, R.P. and Goebel, D.M., "Sputtering Yields of Ion Thruster Grid and Cathode Materials during Very Low Xenon Plasma Bombardment," AIAA-2003-4561, 39 ${ }^{\text {th }}$ AIAA/ASME/SAE/ASEE Joint Propulsion Conference and Exhibit, Huntsville, AL, July 20-23.

59. Van Noord, J. L., "Lifetime Assessment of the NEXT Ion Thruster," AIAA-2007-5274, 43 ${ }^{\text {rd }}$ AIAA/ASME/SAE/ASEE Joint Propulsion Conference and Exhibit, Cincinnati, OH, Jul. 8-11, 2007.

60. Polk, J.E., Duchemin, O.B., Ho, C., and Koel, B.E., "The Effect of Carbon Deposition on Accelerator Grid Wear Rates in Ion Engine Ground Testing," AIAA-2000-3662, 36th AIAA/ASME/SAE/ASEE Joint Propulsion Conference and Exhibit, Huntsville, AL, Jul. 17-19, 2000.

61. Williams, G.J. and Gilland, J.H., "Modeling of the Accelerator Grid Erosion of the NASA Evolutionary Xenon Thruster (NEXT)," NEXT Internal Report, NASA Glenn Research Center, Cleveland, OH, Sep. 2007.

62. Brophy, J.R., et al., "Implementation of the Dawn Ion Propulsion System," AIAA-2005-4071, $41^{\text {st }}$ AIAA/ASME/SAE/ASEE Joint Propulsion Conference and Exhibit, Tucson, AZ, Jul. 10-13, 2005. 


\begin{tabular}{|c|c|c|}
\hline \multicolumn{2}{|c|}{ REPORT DOCUMENTATION PAGE } & $\begin{array}{l}\text { Form Approved } \\
\text { OMB No. 0704-0188 }\end{array}$ \\
\hline \multicolumn{3}{|c|}{$\begin{array}{l}\text { The public reporting burden for this collection of information is estimated to average } 1 \text { hour per response, including the time for reviewing instructions, searching existing data sources, gathering and maintaining the } \\
\text { data needed, and completing and reviewing the collection of information. Send comments regarding this burden estimate or any other aspect of this collection of information, including suggestions for reducing this } \\
\text { burden, to Department of Defense, Washington Headquarters Services, Directorate for Information Operations and Reports (0704-0188), } 1215 \text { Jefferson Davis Highway, Suite } 1224 \text {, Anlington, VA } 222202-4302 \text {. } \\
\text { Respondents should be aware that notwithstanding any other provision of law, no person shall be subject to any penalty for failing to comply with a collection of information if it does not display a currently valid OMB } \\
\text { control number. } \\
\text { PLEASE DO NOT RETURN YOUR FORM TO THE ABOVE ADDRESS. }\end{array}$} \\
\hline $\begin{array}{l}\text { 1. REPORT DATE (DD-MM-YYYY) } \\
01-11-2010\end{array}$ & $\begin{array}{l}\text { 2. REPORT TYPE } \\
\text { Technical Memorandum }\end{array}$ & 3. DATES COVERED (From - To) \\
\hline \multirow{3}{*}{\multicolumn{2}{|c|}{$\begin{array}{l}\text { 4. TITLE AND SUBTITLE } \\
\text { Status of the NASA's Evolutionary Xenon Thruster (NEXT) Long-1 } \\
\text { 30,352 Hours of Operation }\end{array}$}} & 5a. CONTRACT NUMBER \\
\hline & & 5b. GRANT NUMBER \\
\hline & & 5c. PROGRAM ELEMENT NUMBER \\
\hline \multirow{3}{*}{\multicolumn{2}{|c|}{$\begin{array}{l}\text { 6. AUTHOR(S) } \\
\text { Herman, Daniel, A. }\end{array}$}} & 5d. PROJECT NUMBER \\
\hline & & 5e. TASK NUMBER \\
\hline & & $\begin{array}{l}\text { 5f. WORK UNIT NUMBER } \\
\text { WBS 346620.04.08.02.01.01 }\end{array}$ \\
\hline \multicolumn{2}{|c|}{$\begin{array}{l}\text { 7. PERFORMING ORGANIZATION NAME(S) AND ADDRESS(ES) } \\
\text { National Aeronautics and Space Administration } \\
\text { John H. Glenn Research Center at Lewis Field } \\
\text { Cleveland, Ohio 44135-3191 }\end{array}$} & $\begin{array}{l}\text { 8. PERFORMING ORGANIZATION } \\
\text { REPORT NUMBER } \\
\text { E-17448 }\end{array}$ \\
\hline \multirow{2}{*}{\multicolumn{2}{|c|}{$\begin{array}{l}\text { 9. SPONSORING/MONITORING AGENCY NAME(S) AND ADDRESS(ES) } \\
\text { National Aeronautics and Space Administration } \\
\text { Washington, DC 20546-0001 }\end{array}$}} & $\begin{array}{l}\text { 10. SPONSORING/MONITOR'S } \\
\text { ACRONYM(S) } \\
\text { NASA }\end{array}$ \\
\hline & & $\begin{array}{l}\text { 11. SPONSORING/MONITORING } \\
\text { REPORT NUMBER } \\
\text { NASA/TM-2010-216817 }\end{array}$ \\
\hline \multicolumn{3}{|c|}{$\begin{array}{l}\text { 12. DISTRIBUTION/AVAILABILITY STATEMENT } \\
\text { Unclassified-Unlimited } \\
\text { Subject Category: } 20 \\
\text { Available electronically at http://gltrs.grc.nasa.gov } \\
\text { This publication is available from the NASA Center for AeroSpace Information, 443-757-5802 }\end{array}$} \\
\hline
\end{tabular}

\section{SUPPLEMENTARY NOTES}

\section{ABSTRACT}

The NASA's Evolutionary Xenon Thruster (NEXT) program is tasked with significantly improving and extending the capabilities of current state-of-the-art NSTAR thruster. The service life capability of the NEXT ion thruster is being assessed by thruster wear test and lifemodeling of critical thruster components, such as the ion optics and cathodes. The NEXT Long-Duration Test (LDT) was initiated to validate and qualify the NEXT thruster propellant throughput capability. The NEXT thruster completed the primary goal of the LDT; namely to demonstrate the project qualification throughput of $450 \mathrm{~kg}$ by the end of calendar year 2009. The NEXT LDT has demonstrated 30,352 hr of operation and processed $490 \mathrm{~kg}$ of xenon throughput--surpassing the NSTAR Extended Life Test hours demonstrated and more than double the throughput demonstrated by the NSTAR flight-spare. Thruster performance changes have been consistent with a priori predictions. Thruster erosion has been minimal and consistent with the thruster service life assessment, which predicts the first failure mode at greater than $750 \mathrm{~kg}$ throughput. The life-limiting failure mode for NEXT is predicted to be loss of structural integrity of the accelerator grid due to erosion by charge-exchange ions.

\section{SUBJECT TERMS}

Ion engines; Ion optics; Ion propulsion; Electric propulsion; Electrostatic propulsion; Plasma propulsion

\begin{tabular}{|c|c|c|c|c|c|}
\hline \multicolumn{3}{|c|}{ 16. SECURITY CLASSIFICATION OF: } & \multirow{2}{*}{$\begin{array}{l}\text { 17. LIMITATION OF } \\
\text { ABSTRACT } \\
\text { UU }\end{array}$} & \multirow{2}{*}{$\begin{array}{l}\text { 18. NUMBER } \\
\text { OF } \\
\text { PAGES } \\
42\end{array}$} & \multirow{2}{*}{$\begin{array}{l}\text { 19a. NAME OF RESPONSIBLE PERSON } \\
\text { STI Help Desk (email:help@sti.nasa.gov) } \\
\text { 19b. TELEPHONE NUMBER (include area code) } \\
\text { 443-757-5802 }\end{array}$} \\
\hline $\begin{array}{l}\text { a. REPORT } \\
\text { U }\end{array}$ & $\begin{array}{l}\text { b. ABSTRACT } \\
\text { U }\end{array}$ & $\begin{array}{l}\text { c. THIS } \\
\text { PAGE } \\
\text { U }\end{array}$ & & & \\
\hline
\end{tabular}



